\title{
Consequences of different air-sea feedbacks on ocean using MITgem and MERRA-2 forcing: Implications for Coupled Data Assimilation Systems
}

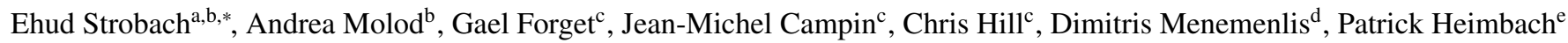 \\ ${ }^{a}$ University of Maryland, College Park \\ ${ }^{b}$ Goddard Space Flight Center \\ ${ }^{c}$ Massachusetts Institute of Technology \\ ${ }^{d}$ Jet Propulsion Laboratory \\ ${ }^{e}$ University of Texas at Austin
}

\begin{abstract}
Ocean surface flux estimates from atmospheric and oceanic reanalyses contain errors that compensate for inaccuracies in the respective atmosphere and ocean models used to generate these reanalyses. A conundrum for climate studies is the discrepancy between surface fluxes that minimize model-data differences for an atmosphere-only model vs surface fluxes that minimize modeldata differences for an ocean model. As a first step towards a consistent coupled ocean-atmosphere data-assimilation (DA) system, we compare surface net heat flux from a state-of-the-art atmospheric reanalysis, the Modern-Era Retrospective analysis for Research and Applications, Version 2 (MERRA-2), to net heat flux from a state-of-the-art ocean state estimate, the Estimating the Circulation and Climate of the Ocean Version 4 (ECCO-v4).

The possible impacts of the MERRA-2 and ECCO-v4 air-sea net heat flux difference in a coupled DA system were assessed using a set of experiments designed to imitate different "flavors" of a coupled DA system in an ocean-only setup. This was done by forcing the ECCO-v4 underlying ocean model - the Massachusetts Institute of Technology general circulation model (MITgcm) with different sets of MERRA-2 fields and utilizing different forcing methods. By doing so we were able to turn off different air-sea feedbacks which, in a coupled DA setup, are partially muted by the constraining observations. The set of experiments, therefore, represents a range of active feedbacks in different "flavors" of coupled data-assimilation systems.

For the period 1992-2011, MERRA-2 net heat flux has a global mean difference of $-4.9 \mathrm{~W} \mathrm{~m}^{-2}$ relative to ECCO-v4. When MERRA-2 surface fields are used to force MITgcm, imbalances in the energy and the hydrological cycles of MERRA-2, which are directly related to the fact that MERRA-2 was created without an interactive ocean, propagate to the ocean. The experiment in which MITgcm is forced with MERRA-2 fluxes (MERRA-2-flux experiment) results in a $2.5^{\circ} \mathrm{C}$ global mean Sea Surface Temperature (SST) cooling, a 1m reduction in global mean sea level, and other drastic changes in the large scale ocean circulation relative to those resulting when the MITgcm is forced with the optimized ECCO-v4 net heat flux (the ECCO-v4 experiment itself). When MITgcm is forced with MERRA-2 state variables (MERRA-2-state experiment), the SST is somewhat restored to the observed SST, but the errors are shifted to the water cycle, resulting in a global mean sea level increase of $2.7 \mathrm{~m}$. To further explore the pros and cons of these two approaches, we introduce a new intermediate forcing method in which the ocean is forced with turbulent fluxes but has a long wave feedback. This method, unlike MERRA-2 state, preserves the MERRA-2 water and salinity cycles, and it reduces the SST error compared to the MERRA-2-flux experiment, but the SST is not as good as that in the MERRA-2-state experiment. Our results have implications for ocean-model forcing recipes and clearly reveal the undesirable consequences of limiting the feedbacks in either these types of experiments or in coupled DA.
\end{abstract}

Keywords: ocean modeling, bulk formulae, atmospheric reanalysis, ocean reanalysis

\section{Introduction}

In recent years the availability of faster computers along with advances in the fidelity of atmosphere-ocean coupled models has brought about a shift towards running large, fully coupled systems and away from studies using forced ocean general circulation models (OGCMs). In addition, near-real time observations of the ocean (Schiller et al., 2016; Legler et al., ${ }_{15}$

\footnotetext{
${ }^{*}$ Corresponding author

Email address: strobach@umd.edu (Ehud Strobach )
}

2015; Le Traon, 2013) and near real time high resolution observations of the atmosphere, such as the GOES-R (Schmit et al., 2017), are now available to provide observational constraints for a coupled atmosphere-ocean data-assimilation (DA) system (Dee et al., 2014). A coupled DA system can assimilate both atmospheric and oceanic observations into a single state estimate and perhaps help address the long standing issues of closing the energy budgets (Trenberth et al., 2016). While the development, validation and operational implementation of such a coupled DA system is a daunting task (Brassington et al., 2015), it is important to test the building blocks of such a system, such 
as the atmosphere-ocean coupled model, since most of these

models suffer from biases (Zuidema et al., 2016; Mogensen et al., 2017). Experimenting with the forced ocean-only setup still has many uses, such as testing and improving oceanice model components before integration into coupled models, 80 studying oceanic processes, and producing regional and global

25 ocean DA analyses for operational and scientific applications. Such an exercise has proved to be valuable in the usage of ECMWF ERA-40 atmospheric reanalysis fields (Brodeau et al., 2010).

Atmospheric reanalysis products such as the Modern-Era

30 Retrospective analysis for Research and Applications, Version 2 (MERRA-2; Gelaro et al., 2017) or the Japanese 55-year Reanalysis (JRA-55; Kobayashi et al., 2015) are readily available to force ocean-ice models. Such reanalysis products aim to pro- 90 vide the most realistic atmospheric state by combining satellite-

35 based and conventional observations into a modeling framework such as the Goddard Earth Observing System Model, Version 5 (GEOS-5; Rienecker et al., 2008; Molod et al., 2015). Usually, atmospheric reanalyses are generated without an inter- 95 active ocean (e.g., Kalnay et al., 1996; Dee et al., 2011; Kobayashi 40 et al., 2015), in which case ocean-atmosphere fluxes are calculated using a prescribed Sea Surface Temperature (SST). An exception to this is the Climate Forecast System Reanalysis (CFSR; Saha et al., 2010), which runs both atmospheric and ${ }_{100}$ oceanic DA systems and relaxes SST to an observation-based

45 dataset. The CFSR DA procedure is performed on a coupled ocean-atmosphere model state, but the analyses for the atmosphere and ocean states are independent of each other.

Recently, several DA groups have investigated different "fla-105 vors" of coupled DA systems that include an iterative DA proso cess in order to allow the influence of ocean observations on the atmospheric reanalysis and the influence of atmospheric observations on the ocean reanalysis (e.g., Laloyaux et al., 2016; Lea et al., 2015). There are still many challenges that need to be ${ }_{110}$ overcome in coupled DA (Dee et al., 2014; Brassington et al., 2015). One such example, relevant to our study, is the need to reduce air-sea exchange/flux biases in the uncoupled form of the model components (Brassington et al., 2015).

Ocean surface heat flux estimates from atmospheric reanal- 115 yses are suboptimal for driving ocean simulations because they

60 project atmospheric model errors onto the surface fluxes via unphysical analysis increments. In addition, the ocean models themselves contain errors, which may cause them to drift away from ocean observations, even if they were forced by ac-120 curate surface fluxes. To reduce these ocean model drifts, sev65 eral methods have been devised for adjusting raw atmospheric reanalysis surface fluxes, for example, the methods devised by the Estimating the Circulation and Climate of the Ocean ECCO project (Forget et al., 2015a), the Simple Ocean DA ocean/sea ${ }_{125}$ ice reanalysis (SODA; Carton et al., 2000b,a), the Coordinated

70 Ocean-ice Reference Experiments Phase 2 (CORE-II; Griffies et al., 2009), the DRAKKAR group (DRAKKAR; Brodeau et al., 2010), and the JRA55-based data set for Driving Ocean-sea ice models (JRA-55-do; Komuro et al., 2017, personal communica-130 tion). The adjusted air-sea fluxes are used to drive ocean models 75 and reduce biases relative to ocean observations.
In analogy to atmospheric reanalyses, ocean state estimation is aimed at providing the most realistic ocean conditions by combining ocean observations and an ocean model, and it is usually carried out without an interactive atmosphere. The lack of feedbacks or coupling between oceanic and atmospheric reanalyses may result in air-sea flux errors since the surface of the atmosphere is not adjusted to changes in the surface of the ocean.

Three methods are commonly used to provide air-sea heat fluxes to force ocean-ice models (Griffies et al., 2009): relaxing SST to prescribed values; providing surface fluxes from observation-based products and reanalyses; and providing atmospheric surface state variables to calculate air-sea fluxes interactively using bulk formulae and a black body radiation calculation. The interactive ocean model's SST feeds back to the air-sea fluxes in the first and third method only.

Relaxing SST to prescribed values is probably the oldest and simplest way to force ocean models (Haney, 1971). It has the advantage that it does not require any atmospheric information as SST is the only field that needs to be specified. However, this method does not constrain air-sea fluxes to be realistic in any way since the air-sea heat fluxes are only a function of the difference between the observed and modeled SST (Seager et al., 1995). Moreover, when relaxing the ocean to observed SST, there is no link between the hydrological and thermal forcing since the evaporation and latent heat flux are not consistent with each other.

In the second method, realistic surface fluxes are directly applied to the ocean model and the SST is allowed to evolve freely without feedback between the ocean and the atmosphere, which can lead to large model drift. For example, a global mean positive downward heat flux can heat the ocean indefinitely without releasing any of the excess heat back to the atmosphere. In this case, there is a link between the thermal and hydrological forcing but it is provided solely by the atmospheric reanalysis.

The interactive surface flux calculation method tends to reduce model drift by allowing feedbacks via latent and sensible heat fluxes (using bulk formulae) and allowing the emitted long wave radiation to change as a function of the ocean model's predicted SST. In this case, positive (negative) downward heat flux to the ocean will increase (decrease) the SST and result in an increased (decreased) upward heat flux to the atmosphere. This negative feedback will damp the positive (negative) heat flux. A link between the hydrological and thermal forcing is provided by the calculation of the latent heat in the bulk formulae and its direct connection to evaporation. The use of reanalysis fields as input to the bulk formulae ensures some degree of realism for the resulting air-sea fluxes. This method may thus be a useful compromise and is the most commonly used today for oceanonly numerical simulations.

Insights can be gained about coupled DA using the different forcing methods, in particular when experiments using them are intercompared. In coupled DA, feedbacks between the ocean and the atmosphere are active, but, depending on the coupled DA system "flavor", they are constrained by the observations (wherever and whenever they are available). An ocean 
model forced with surface fluxes (like the MERRA-2-flux experiment described later) is a useful analogy to a very tightly radiation feedback ("MERRA-2-turb") acts to reduce the constraints through the changing SST, and adding turbulent flux feedbacks ("MERRA-2-state") acts to reduce the constraints even more. In this context a free running coupled model is the ating freely and can be expected to push the model to its own quasi-balanced state. Coupled DA systems, in which the active feedbacks are constrained by the data to an extent that depends on the "flavor" of the coupled DA system, can be expected to ocean-only experiments discussed here.

In addition to the analysis and understanding of the role of different feedbacks on the simulated ocean, this study provides useful steps towards the development of a coupled atmospherean model and DA system that includes the atmospheric moded that underlies the MERRA-2 atmospheric reanalysis and the ocean model that underlies the ECCO-v4 ocean state estimate. These are the Goddard Earth Observing System general circulation model (GEOS-GCM) and the Massachusetts Institute of

155 Technology general circulation model $(\mathrm{MITgcm})$. The coupled ${ }_{210}$ DA system will exploit and leverage the MERRA-2 and ECCOv4 DA capabilities.

In this study we first compare air-sea net heat flux estimates from MERRA-2 and ECCO Version 4, Release 2 (here-

${ }_{160}$ inafter ECCO-v4; Forget, 2016). Next we use a set of controlled ${ }_{215}$ ocean-only experiments to investigate the impact of MERRA-2 atmospheric forcing on an ECCO-v4 configuration of the MIT$\mathrm{gcm}$, with particular focus on ocean-atmosphere feedbacks and their misrepresentation in forced ocean models. We use differ-

165 ent ocean-model forcing methods to investigate the effect of the 220 different feedbacks, in combination and one at a time, on the MITgcm ocean simulations.

Section 2 describes the MITgcm configuration and the ECCOv4 and MERRA-2 fields, which are used in this study. Sec-

170 tion 3 compares MERRA-2 and ECCO-v4 net surface heat flux 225 and presents results from the MITgcm simulations forced by MERRA-2 fields, with emphasis on the impact of different feedback mechanisms. Section 4 examines the same MITgcm simulation results in terms of the misfit between the model and ocean observations. The study is summarized in section 5, where con-2зо clusions are drawn and implications for coupled DA are discussed.

\section{Models and Data}

The ECCO project was established in 1998 as part of the ${ }_{180}$ World Ocean Circulation Experiment (WOCE) with the goal of combining an OGCM with diverse observations in order to produce a quantitative depiction of the time-evolving global ocean state without violating conservation of momentum, heat, and ${ }_{240}$ salt resulting from analysis increments (Stammer et al., 2002;

185 Wunsch et al., 2009). This study uses ECCO-v4, Release 2 solution, which covers 1992 to 2011 and is based on the MITgcm ocean-ice model.
ECCO-v4 is based on the MITgcm ocean-ice model, and its configuration and first release solution are discussed in Forget et al. (2015a). Briefly, the MITgcm, as configured in ECCO$\mathrm{v} 4$, solves the hydrostatic Boussinesq equations (Marshall et al., 1997) using rescaled $z^{*}$ coordinates (Adcroft and Campin, 2004) and a nonlinear free surface with real freshwater flux surface boundary conditions (Campin et al., 2004). The grid used is the "Lat-Lon-Cap-90" (LLC90), which has a nominal horizontal grid spacing of $1^{\circ}$ and 50 vertical levels. Sea-ice in the ECCO-v4 configuration is fully interactive and based on the Losch et al. (2010) model. The forcing used in ECCO-v4 is based on the bulk formulae of Large and Yeager (2004) and an adjusted version of the European Centre for Medium-Range Weather Forecasts (ECMWF) interim reanalysis (ERA-Interim; Dee et al., 2011) surface atmospheric fields. The ERA-Interim surface forcing (radiative fluxes, surface state, wind stress, etc...), along with parameterized physics in the ocean interior and the 1992 initial conditions, were adjusted iteratively within the ECCOv4 inverse modeling framework so that the 20-year model trajectory closely fits ocean observations (Forget et al., 2015a; Forget and Ponte, 2015; Forget et al., 2015b). For the sensitivity experiments described in this study, we only replace the surface boundary conditions while retaining all other ECCO-v4 settings, including initial conditions and optimized estimates of isopycnal and cross-isopycnal mixing parameters (Forget, 2016).

MERRA-2 was developed by the NASA Global Modeling and Assimilation Office (GMAO) and is described in Gelaro et al. (2017). The underlying atmospheric general circulation model (AGCM) is the GEOS-5 atmospheric model. It includes the dynamical core of Putman and Lin (2009). Its horizontal grid is a cubed sphere, with an approximate grid spacing of $0.5^{\circ}$ in latitude and $0.625^{\circ}$ in longitude, with 72 hybrid-eta levels from the surface to $0.01[h P a]$. Surface fluxes are computed using prescribed SST and the surface parameterization of turbulent fluxes described in Molod et al. (2015). In short, it is a modified version of the parameterization documented in Helfand and Schubert (1995), with a wind stress-surface roughness model modified by the updates of Garfinkel et al. (2011) for a mid-range of wind speeds, and further modified by the updates of Molod et al. (2013) for high winds.

DA in MERRA-2 was done using a three-dimensional variational (3D-Var) algorithm based on the Gridpoint Statistical Interpolation (GSI) analysis scheme (Gelaro et al., 2017). The correction of the background state was applied using the Incremental Analysis Update (IAU) procedure of Bloom et al. (1996).

The simulations conducted here used the MITgcm in its ECCO-v4 configuration. The only difference between ECCO$\mathrm{v} 4$ and the experiments presented here is the use of forcing data from non-adjusted MERRA-2 reanalysis in place of the 4D-Var/adjoint adjusted ERA-Interim based atmospheric fields. We present experiments using three different forcing methods (Table 1). The first method called "MERRA-2-flux" uses the MERRA-2 fluxes directly without allowing any SST feedbacks. The second method called "MERRA-2-state" uses MERRA-2 state variables as input to the MITgcm bulk formulae (Large 
Table 1: Forcing fields and feedbacks in MERRA-2-flux, MERRA-2-state, and MERRA-2-turb. Where, ustress and vstress are the surface zonal and meridional wind stress, swflux and lwflux are the short and long wave radiation heat fluxes, hs and hl are the sensible and latent heat fluxes, evap is the evaporation, precip is the precipitation, swdown and lwdown are the downward short and long wave radiation heat fluxes, atemp is surface temperature, aqh is surface specific humidity, wspeed is surface wind speed, lwnet is the net long wave radiation and lwup is the upward long wave radiation heat flux

\begin{tabular}{llll}
\hline \hline & MERRA-2-flux & MERRA-2-state & MERRA-2-turb \\
\hline \hline Forcing data & $\begin{array}{l}\text { ustress, vstress, swflux, } \\
\text { lwflux, hs, hl, evap, precip }\end{array}$ & $\begin{array}{l}\text { ustress, vstress, swdown, } \\
\text { lwdown, atemp, aqh, precip, } \\
\text { wspeed }\end{array}$ & $\begin{array}{l}\text { ustress, vstress, swdown, } \\
\text { lwdown, hs, hl, evap, precip }\end{array}$ \\
\hline Runoff & Fekete et al. (2002) & Fekete et al. (2002) & Fekete et al. (2002) \\
\hline Sea-ice forcing & $\begin{array}{l}\text { atemp, aqh, wspeed, } \\
\text { swdown, lwdown }\end{array}$ & - & atemp, aqh, wspeed \\
\hline Interactive variables & - & hs, hl, lwnet (lwup) & lwnet (lwup) \\
\hline
\end{tabular}

and Yeager, 2004) which calculates the heat and evaporative fluxes, and uses the MERRA-2 wind stress. In this method, tur-285 bulent heat fluxes, evaporation, and upward long wave radiation are interactive with the simulated SST. In a third intermediate method called "MERRA-2-turb", the MERRA-2 turbulent heat fluxes are used, but the upward long wave radiation is computed based on the simulated SST. Sea-ice, as implemented in 290 MITgcm can only be forced by computing a sea-ice-specific set of bulk formulae, so all three solutions use the same forcing method over sea-ice and the results and discussion below are mostly restricted to the domain between the latitudes of $60^{\circ} \mathrm{S}$ to $60^{\circ} \mathrm{N}$.

We compare MERRA-2 individual components of air-sea fluxes with observation-based products from GSSTF2 (Chou et al., 2003), GEWEX SRB (Stackhouse Jr et al., 2011), OAFlux (Yu and Weller, 2007) and ISCCP (Zhang et al., 2004). Although these products are observation-based, they are not di-300 rect measurements and have their own limitations. Differences between the reanalyses and observation-based datasets can be attributed to errors in both types of data products, differences between the input data they use and other structural differences, such as temporal and spatial resolution and differences in sam-305 pling. While the observation-based datasets are constrained only by surface data, reanalysis data are also influenced by deep ocean or upper atmosphere observations. Therefore, each of the two product families may have its own limitations and advantages.

\section{Results of Ocean Model Experiments}

\subsection{MERRA-2 versus ECCO-v4 total net heat flux}

For the purpose of evaluating the net heat flux that will be ${ }^{315}$ used to force the ocean-only simulations presented here against what the MITgcm ocean model is in relative equilibrium with, we compare the MERRA-2 and ECCO-v4 net air-sea heat fluxes, Figure 1. The net heat flux (left) shows similar spatial patterns in ECCO-v4 and MERRA-2, but there are notable differences ${ }^{320}$ such as MERRA-2 strong negative heat flux in the Maritime Continent and North Indian Ocean and the positive heat flux in the Northern Pacific, Eastern Central Pacific, Eastern Atlantic, and Eastern Central Indian Ocean.
The global (see also Table 3) net heat flux is reduced in MERRA-2 $\left(-4.6 \mathrm{~W} \mathrm{~m}^{-2}\right)$ compared to ECCO-v4 $\left(0.3 \mathrm{~W} \mathrm{~m}^{-2}\right)$, such that the global mean net heat flux has opposite sign in MERRA-2 and ECCO-v4. Observation-based estimates of global mean net heat flux to the ocean during the last three decades typically range between $0.5 \mathrm{~W} \mathrm{~m}^{-2}$ and $0.8 \mathrm{~W} \mathrm{~m}^{-2}$ (e.g., Allan et al., 2014; Johnson et al., 2016) (not considering reanalysis products that have a much larger range (Balmaseda et al., 2015; Valdivieso et al., 2017)).

A 20-year heating deficit such as that of MERRA-2 $(\approx 5$ $\mathrm{W} \mathrm{m}{ }^{-2}$ over the domain in Figure 1) can cool a $100 \mathrm{~m}$ ocean layer by $\Delta T \approx\left[5 \mathrm{~W} / \mathrm{m}^{2}\right] \cdot \frac{31,536,000[\mathrm{~s} / \text { year }] \cdot 20[\text { year }]}{4200\left[\mathrm{~J} / \mathrm{kg} /{ }^{\circ} \mathrm{C}\right] \cdot 1000\left[\mathrm{~kg} / \mathrm{m}^{3}\right] \cdot 100[\mathrm{~m}]} \approx 7.5\left[^{\circ} \mathrm{C}\right]$. MERRA-2's large negative net heat flux compared to ECCO$\mathrm{v} 4$ thus can have a direct and rapid impact on the near-surface ocean (time scale of days) and a longer and indirect impact on the the deep ocean (time scale of days to millennial).

Figure 1 also shows that the SSTs in MERRA-2 and ECCOv4 are similar. MERRA-2 uses a combination of Taylor et al. (2000), Reynolds et al. (2002, 2007), and Donlon et al. (2012) SST as described in (Bosilovich et al., 2015b). ECCO-v4 constrains the MITgcm SST to that of Reynolds (Forget et al., 2015a). The right column of Figure 1 shows that the two SST patterns are very similar to within a small ECCO-v4 mean positive difference of $\approx-0.42^{\circ} \mathrm{C}$.

In Table 2 we show the partition of the MERRA-2 global net heat flux into its four components and compare them with observation-based products. The MERRA-2 heat flux components are generally lower compared to the observation-based products. The low radiation values shown here relative to all of the observation-based estimates were demonstrated by Bosilovich (2015) to be related to cloud forcing or water vapor issues in MERRA-2. Uncertainties in the observation-based products are also large and, for example, it is known that OAFlux-ISCCP combination leads to $30 \mathrm{~W} \mathrm{~m}^{-2}$ excess heat flux (OAFLUX, 2018). The maps in the Appendix show that observation-based products often differ from one another as much as they differ from MERRA2.

\subsection{MITgcm forced with MERRA-2 fluxes}

In an ideal scenario, surface fluxes in a coupled DA system would force an ocean model to the ocean reanalysis solution. 

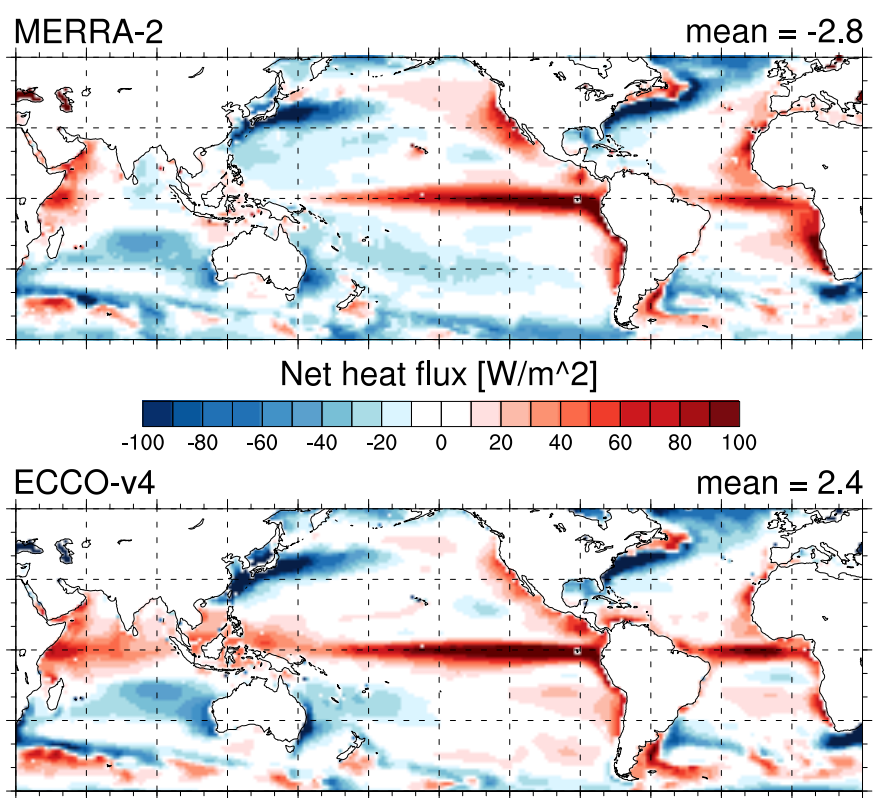

Net heat flux $\left[\mathrm{W} / \mathrm{m}^{\wedge} 2\right]$

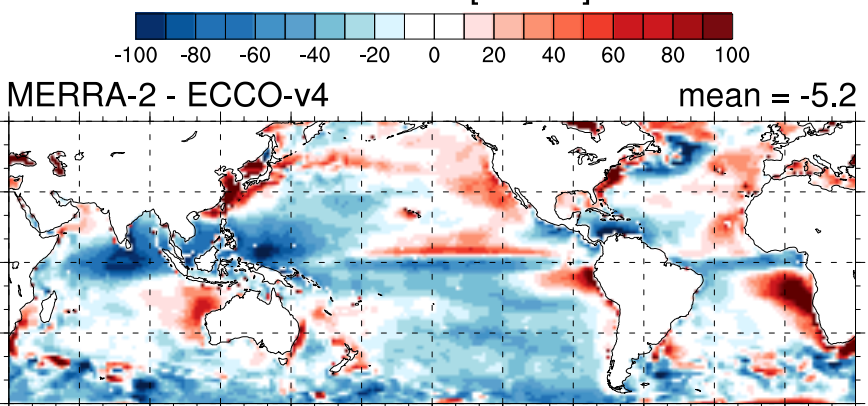

Net heat flux $\left[\mathrm{W} / \mathrm{m}^{\wedge} 2\right]$

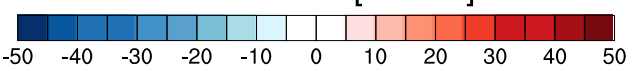

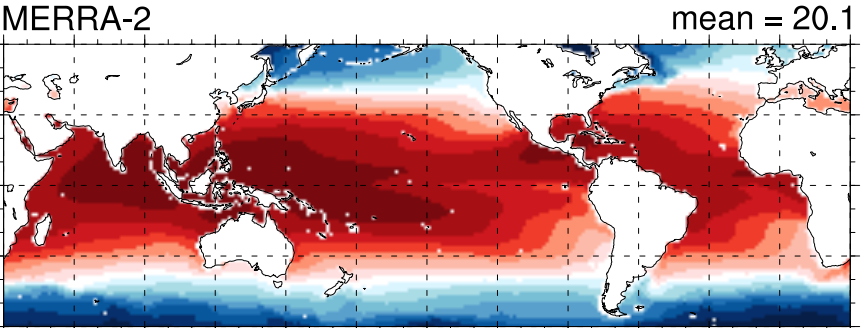

SST [DegC]
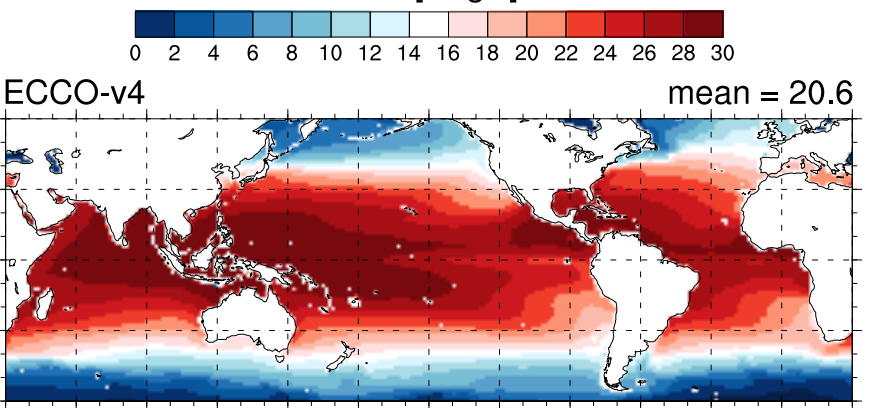

SST [DegC]

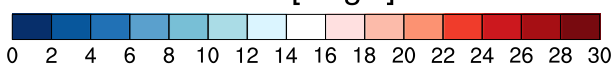

mean $=-0.4$

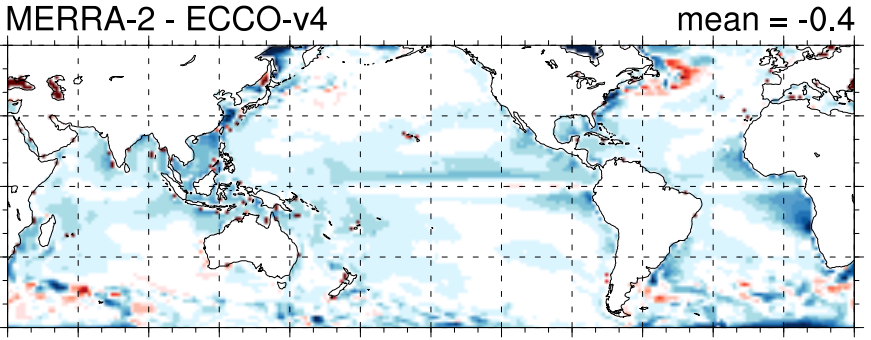

SST $[\mathrm{DegC}]$

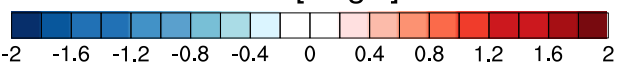

Figure 1: Spatial distribution of the 20-year averaged net heat flux (first row) in $W^{-2}$ for MERRA-2 (left column), ECCO-v4 (middle column), and their difference (right column). SST from MERRA-2 (left column), ECCO-v4 (middle column), and their difference (right column) is shown in the bottom row (in ${ }^{\circ} \mathrm{C}$ ).

Table 2: $60^{\circ} \mathrm{S}-60^{\circ} \mathrm{N}$ and time averaged surface flux components of MERRA-2 versus observation-based products in $\mathrm{W} \mathrm{m}^{-2}$ (mean difference and standard deviation in parenthesis, maps are shown in Figures A.1-A.4 in the Appendix).

\begin{tabular}{|l|c|c|c|c|c|}
\hline \hline & MERRA-2 & MERRA-2 - GSSFTF & MERRA-2 - OAFlux & MERRA-2 - ISCCP & MERRA-2 - SRB \\
\hline \hline Latent heat & -115.7 & $-8.4(25.1)$ & $-14.9(13.1)$ & - & - \\
\hline Sensible heat & -11.8 & $-5.6(4.9)$ & $-1.5(3.1)$ & - & - \\
\hline Long wave & -60.1 & - & - & $-10.7(10.1)$ & $-12.2(7.3)$ \\
\hline Short wave & 182.5 & - & - & $-4.9(14.5)$ & $-8.6(11.6)$ \\
\hline
\end{tabular}

In our case, this would have happened if the MERRA-2 fluxes were identical to the ECCO-v4 fluxes. Moreover, the choice of forcing method would not affect the solution in this case since all methods would have resulted in the same fluxes. How-з35 ever, differences between the MERRA-2 and ECCO-v4 fluxes are sizable. Different forcing methods, therefore, generate so-

Using the MERRA-2 net heat flux from Figure 1 (without

any DA adjustment) as forcing for the MITgcm ocean model in its ECCO-v4 configuration (i.e., the MERRA-2-flux experiment) results in SST biases as shown in Figure 2. Mean SST is reduced because of the negative heat flux imbalance and the lack of restoring feedbacks. The most negative bias is observed in the Southeast Asia Archipelagos and North Indian Ocean (in agreement with the negative net heat flux anomaly in these regions). Regional warm biases are also observed, notably in the 
340 Northern Pacific and Eastern Atlantic. Even though anomalous SST patterns generally reflect anomalous air-sea heat flux pat- ${ }_{370}$ terns, this is not the case for the excess net heat flux found in MERRA-2, relative to ECCO-v4, in the North Tropical Pacific. Strong westward surface currents in this region likely trans345 ported the heat anomaly to the western Pacific and mitigated the cold anomaly there. Overall, there is a small but significant positive correlation $(r=0.15,95 \%$ significant level, von Storch and Zwiers (1999, Chapter 8)) between the cooling pattern in the MERRA-2 minus ECCO-v4 net heat flux (first row, 350 third column in Figure 1) and the resulting SST anomaly of the MERRA-2-flux experiment (lower panel in Figure 2). Other $_{380}$ possible contributions to the different SST pattern are the wind stress and water flux (later, Figure 4 will show that when the net heat flux to the ocean is close to the net heat flux of ECCO-

$355 \mathrm{v} 4$ but the stress and the precipitation are from MERRA-2, the SST is restored to the observed SST).

This MERRA-2-flux experiment is a useful analogy to the active air-sea interface feedbacks in a coupled DA system in which the surface of the atmosphere and top of the ocean are both strongly constrained to atmospheric and oceanic near surface observations. Strong observational constraints serve the ${ }_{390}$ same role as artificial removal of important feedbacks. In a coupled DA system, errors in the ocean model (as the SST errors in MERRA-2-flux) are going to be adjusted towards the observed values by the ocean assimilation process. Therefore, we consider MERRA-2-flux as an amplification of the errors that will propagate from the atmosphere to the ocean in a strongly constrained coupled DA system.

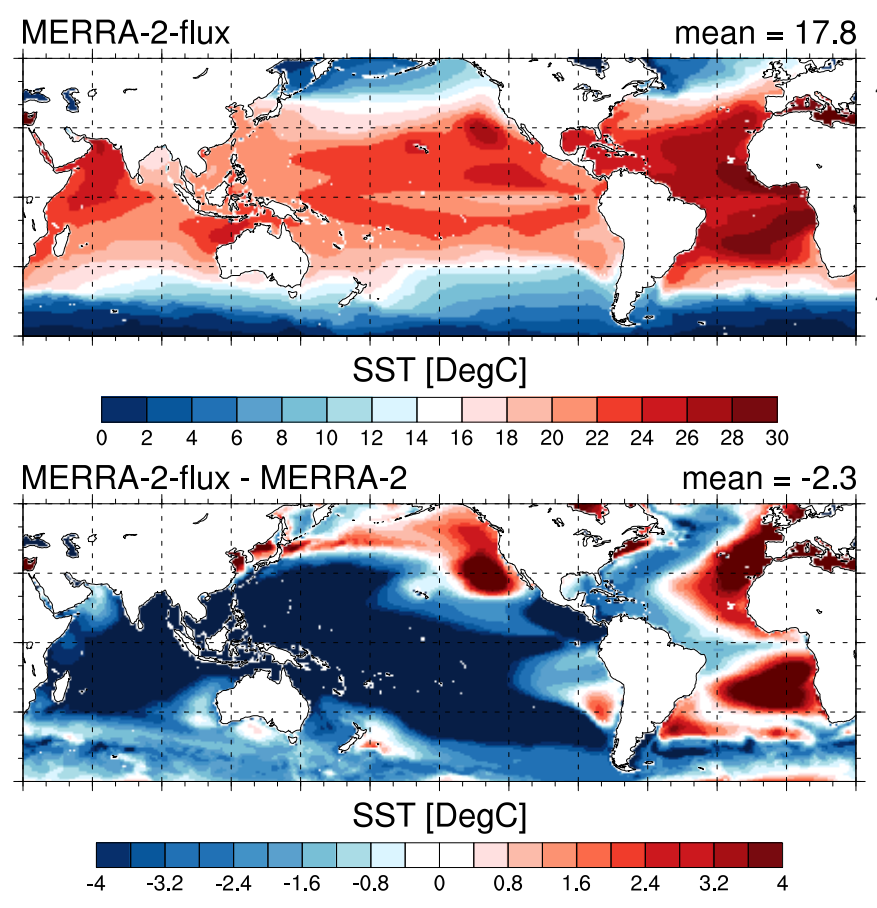

Figure 2: SST 20-year climatology of the MERRA-2-flux experiment (in ${ }^{\circ} \mathrm{C}$ ). The upper panel shows the SST of MITgcm forced with MERRA-2 fluxes and the bottom panel is the difference between MERRA-2-flux SST and MERRA-2 SST.

\subsection{MITgcm forced with MERRA-2 state variables}

When the MITgcm ocean model is forced with MERRA2 state variables using bulk formulae to compute the fluxes (MERRA-2-state), as opposed to using MERRA-2 fluxes directly, the resulting SST is much closer to the SST used in MERRA-2 and the SST estimated in ECCO-v4 (Figure 3, second row, second and third columns). The net heat flux is in much closer agreement with the ECCO-v4 net heat flux than MERRA-2 (Figure 3, first row, second and third columns).

The difference between the net heat flux in the MERRA-2flux and MERRA-2-state experiments mainly occur in the latent heat flux, which increased from $\approx-113 \mathrm{~W} \mathrm{~m}^{-2}$ to $\approx-101$ $\mathrm{W} \mathrm{m} \mathrm{m}^{-2}$ (Figure 4, first row) and brought MERRA-2-state latent heat flux closer (compared with MERRA-2) to observationbased products (Figure A.1). The sensible heat flux correction was negligible, $0.12 \mathrm{~W} \mathrm{~m}^{-2}$ (second row, right) on average, compared with the latent heat correction of $11.9 \mathrm{~W} \mathrm{~m}^{-2}$ (first row, right). The net long wave radiation was reduced by $2.4 \mathrm{~W} \mathrm{~m}^{-2}$ (third row, right) compared with MERRA-2, which increased the difference with the observation-based products (Figure A.3). Thus, it appears that the latent heat flux feedback acted to increase SST, from $17.8^{\circ} \mathrm{C}$ (Figure 2, upper panel) to $20.3^{\circ} \mathrm{C}$ (Figure 3, first row, right), and the black body radiation adjusted accordingly. The net shortwave radiation differs slightly from MERRA-2-flux (forth row, middle) due to a small difference in albedo ( $2 \%)$.

A more positive latent heat flux into the ocean (and so a lower latent heat flux out of the ocean) has a direct influence on the sea surface height since it corresponds to reduced evaporation. The average sea level in MERRA-2-state thus increased by $2.7 \mathrm{~m}$ over 20 years as compared with MERRA-2-flux. This behavior clearly does not reflect a physically reasonable feedback since the atmosphere only carries about $2.6 \mathrm{~cm}$ of sea level equivalent water (Bengtsson, 2010). The increase went in the right direction since MERRA-2-flux (with Fekete et al. (2002) runoff) has a water budget imbalance of $\approx-1 \mathrm{~m}$ over 20 years, but it vastly overshot observed sea level rise. However, imbalances in both MERRA-2-flux and MERRA-2-state are an order of magnitude too large compared with the observed sea-level rise of $\approx 3 \mathrm{~mm}$ year $^{-1}$ over the satellite era of satellite altimetry (Chambers et al., 2017).

To better understand feedbacks as they result from bulk formulae forcing and long wave radiation, it is useful to recall the underlying equations for latent $\left(Q_{E}\right)$ and sensible $\left(Q_{H}\right)$ heat fluxes:

$$
Q_{E}(S S T)=A_{V} \cdot C_{E}(S S T) \cdot\left(q-q_{s a t}(S S T)\right),
$$

and

$$
Q_{H}(S S T)=C_{P} \cdot C_{H}(S S T) \cdot(T 2-S S T),
$$

where $A_{V} \approx 2.5 \times 10^{6}\left[\mathrm{~J} \mathrm{~kg}^{-1}{ }^{\circ} \mathrm{C}^{-1}\right]$ is the latent heat of evaporation and $C_{P} \approx 1000\left[\mathrm{~J} \mathrm{~kg}^{-1}\right]$ is the specific heat of air; $C_{E}$ and $C_{H}$ are surface exchange coefficients for moisture and heat multiplied by the density and wind, respectively; $q_{\text {sat }}=q_{1} / \rho$. $e^{q_{2} / S S T}$, where, $q_{1}=0.98 \cdot 640380\left[\mathrm{~kg} \mathrm{~m}^{-3}\right]$ and $q_{2}=5107.4 \mathrm{~K}$; 


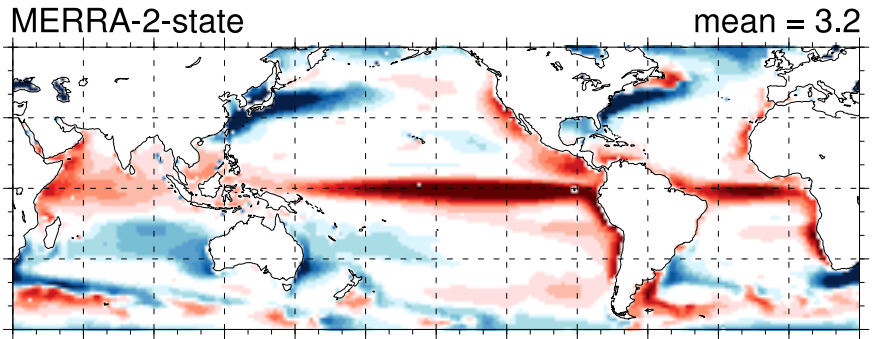

Net heat flux $\left[\mathrm{W} / \mathrm{m}^{\wedge} 2\right]$

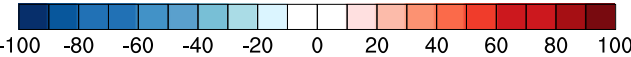

MERRA-2-state - MERRA-2

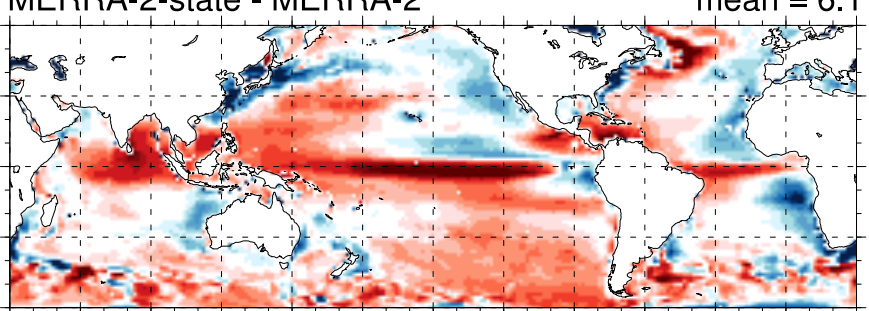

Net heat flux $\left[\mathrm{W} / \mathrm{m}^{\wedge} 2\right]$
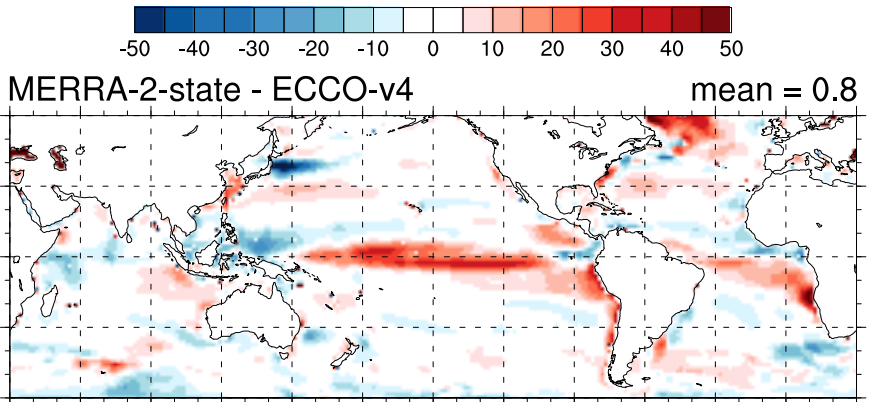

Net heat flux $\left[\mathrm{W} / \mathrm{m}^{\wedge} 2\right]$

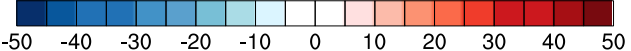

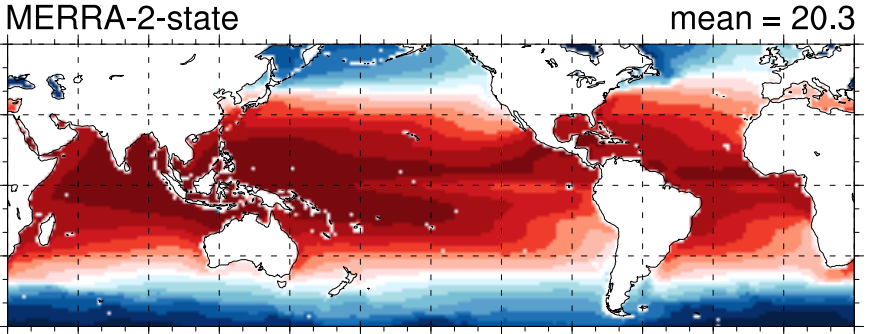
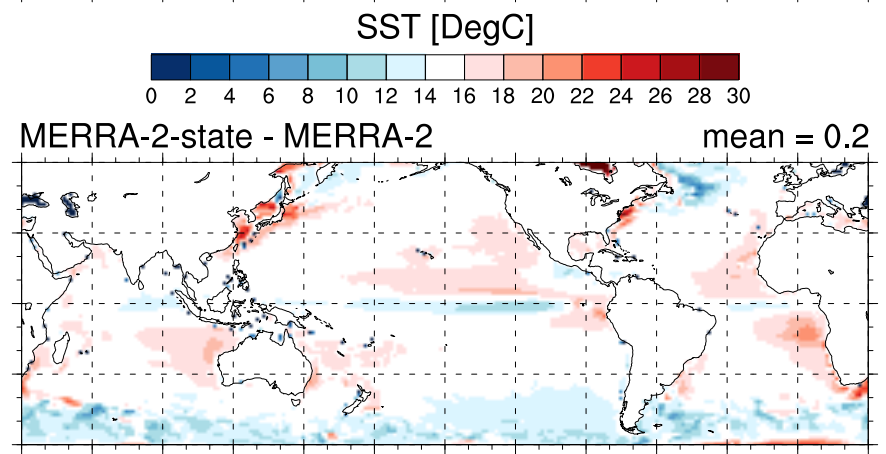

SST [DegC]
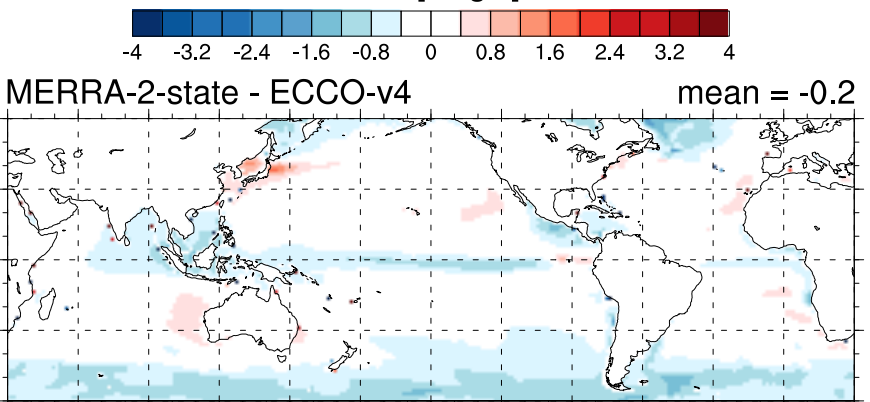

SST [DegC]

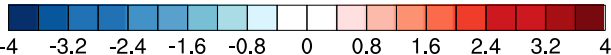

Figure 3: MERRA-2-state spatial distribution of 20-year average of net total surface heat flux (in W $\mathrm{m}^{-2}$ ); and SST (in ${ }^{\circ} \mathrm{C}$ ). The first column shows MERRA-2-state fluxes, the second column shows MERRA-2-state minus the original MERRA-2 fluxes, and the third column shows MERRA-2-state minus ECCO-v4 fluxes.

and $T 2$ is the two-meter air temperature. The governing equation for the long wave radiation is:

$$
Q_{L W}(S S T)=-\epsilon \cdot \sigma \cdot S S T^{4},
$$

where $\epsilon=0.97$ is the ocean emissivity and $\sigma=5.67 \times 10^{-8}\left[\mathrm{~W} \mathrm{~m}^{-2} \mathrm{~K}^{-4}\right]$ is the Stefan-Boltzmann constant.

The total heat flux to the ocean in MERRA-2-state, after linear expansion around MERRA-2 SST ( $\left.S S T_{m}\right)$ and MERRA- ${ }^{420}$ 2 heat exchange coefficients $\left(C_{E}^{M E R R A-2}\right.$ and $\left.C_{H}^{M E R R A-2}\right)$, thus is:

$$
\begin{gathered}
Q_{n e t}^{M E R R A-2 ~ s t a t e}=Q_{n e t}^{M E R R A-2}+\frac{d Q_{E}}{d S S T} \cdot\left(S S T-S S T_{m}\right) \\
+\frac{d Q_{H}}{d S S T} \cdot\left(S S T-S S T_{m}\right)+\frac{d Q_{L W}}{d S S T} \cdot\left(S S T-S S T_{m}\right)+d Q_{S W} \\
+\frac{d Q_{E}}{d C_{E}} \cdot\left(C_{E}^{E C C O-v 4}-C_{E}^{M E R R A-2}\right)+\frac{d Q_{H}}{d C_{H}} \cdot\left(C_{H}^{E C C O-v 4}-C_{H}^{M E R R A-2}\right) .
\end{gathered}
$$

The fifth term on the right hand side of equation (4) represents changes in the shortwave radiation $\left(=-3.3 \mathrm{~W} \mathrm{~m} \mathrm{~m}^{-2}\right.$, spatial and temporal average, Figure 4 row 4 last column) due to different albedo in MITgcm and GEOS5. The last two terms represent differences in the bulk formulae parameterizations.

Direct comparison between the MERRA-2 and MITgcm $C_{E}$ and $C_{H}$ coefficients is difficult since in MERRA-2 they are calculated based on state variables at the top of the surface layer ( $\approx 60 \mathrm{~m}$ above ground) whereas in MITgcm they are calculated based on state variables interpolated in MERRA-2 to a $2 \mathrm{~m}$ height. To assess the differences due to differences in bulk formulae, we applied MERRA-2 bulk formulae to the same 1992 surface variables used to drive MITgcm and compared with MITgcm $C_{E}$ and $C_{H}$ for the same period. The MERRA-2 coefficients were, in general, larger by $5-15 \%$ for latent heat and by $10-50 \%$ for sensible heat compared to the MITgcm coefficients. The SST used to force the MERRA-2 reanalysis is, on average, lower than that of the MERRA-2-state sensitivity experiment by $0.25^{\circ} \mathrm{C}$. In some regions, for example, the Trop- 


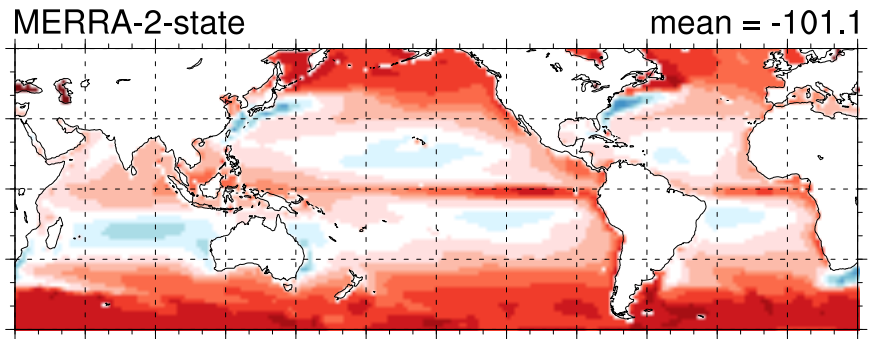

Latent Heat $\left[\mathrm{W} / \mathrm{m}^{\wedge} 2\right]$

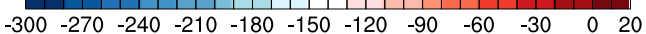

MERRA-2-state

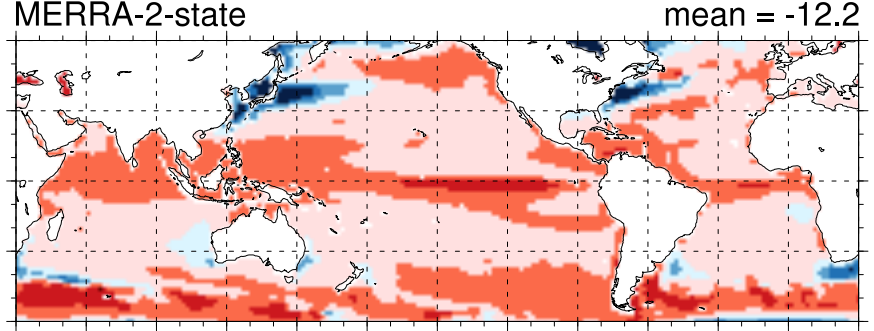

Sensible Heat [W/m^2]
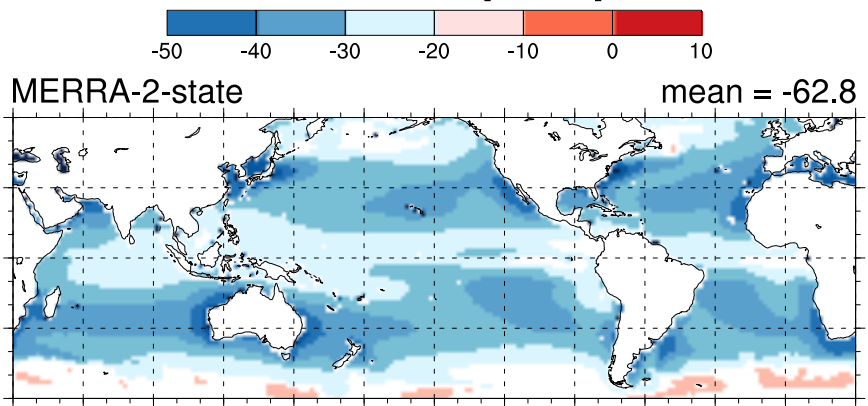

Net long wave radiation [W/m^2]
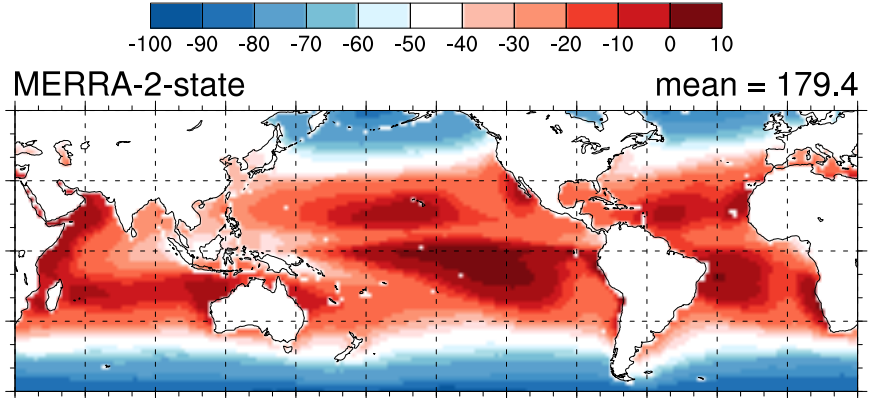

Net short wave radiation $\left[\mathrm{W} / \mathrm{m}^{\wedge} 2\right]$

$\begin{array}{llllllllllll}40 & 60 & 80 & 100 & 120 & 140 & 160 & 180 & 200 & 220 & 240 & 260\end{array}$

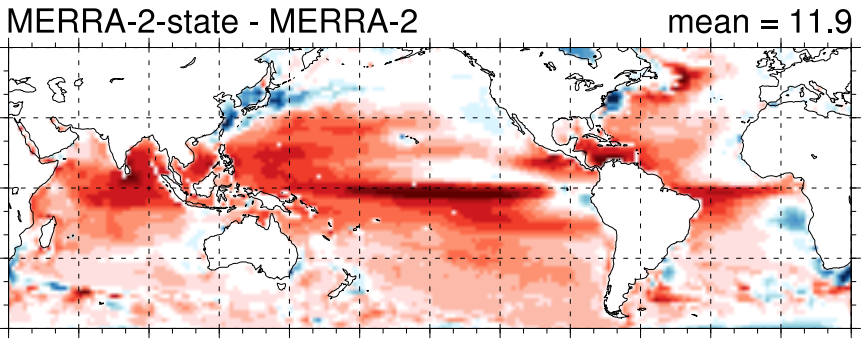

Latent Heat $\left[\mathrm{W} / \mathrm{m}^{\wedge} 2\right]$
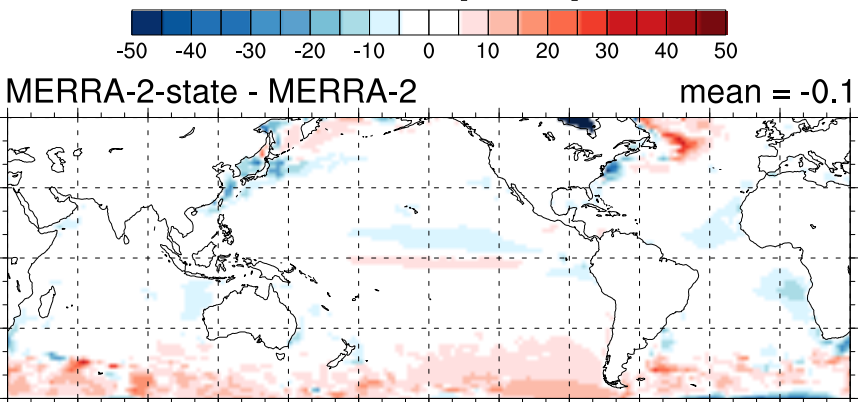

Sensible Heat [W/m^2]
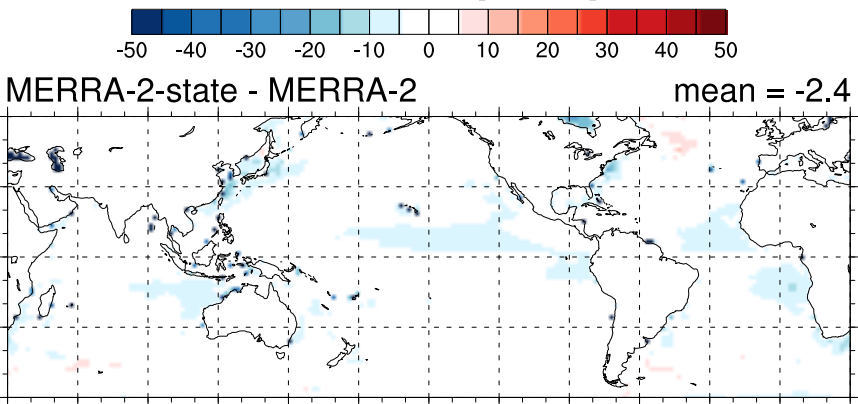

Net long wave radiation $\left[\mathrm{W} / \mathrm{m}^{\wedge} 2\right]$
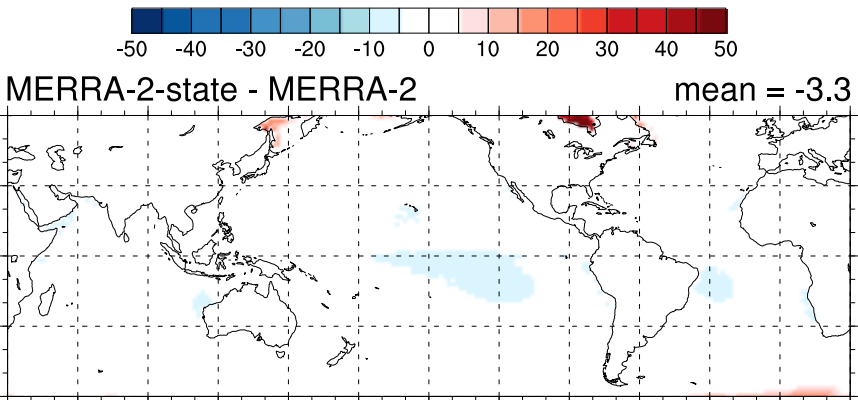

Net short wave radiation $\left[\mathrm{W} / \mathrm{m}^{\wedge} 2\right]$

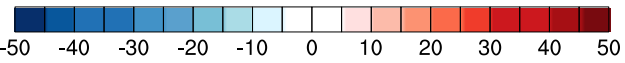

Figure 4: MERRA-2-state spatial distribution of 20-year average of latent heat, sensible heat, net long wave radiation, and net short wave radiation (in $\mathrm{W} \mathrm{m}^{-2}$ ); and SST (in ${ }^{\circ} \mathrm{C}$ ). The first column shows MERRA-2-state fluxes, the second column shows MERRA-2-state minus the original MERRA-2 fluxes, and the third column shows MERRA-2-state minus ECCO-v4 fluxes.

ical Pacific, the difference is as large as $\pm 1^{\circ} \mathrm{C}$.

Figure 5 shows the effect of differences in SST and exchange coefficients on the resulting heat flux. The upper panel $1_{40}$ shows the $2 \mathrm{nd}, 3 \mathrm{rd}$, and 4 th terms on the right hand side of eq. (4). In the case of latent and sensible heat, the derivative takes into account the dependence of the $C_{E}$ and $C_{H}$ coefficient on SST. The middle panel shows the differences between the
GEOS and MITgem $C_{E}$ (6th term in the right-hand side of eq. 4). The lower panel depicts the differences between the GEOS5 and MITgcm $C_{H}$ (7th term in the right-hand side of eq. 4). The parameters $\Delta C_{E}=0.001$ and $\Delta C_{H}=0.001$ where chosen to represent differences of $\approx 10 \%$.

The upper panel in Figure 5 shows that for $\mathrm{SST} \gtrsim 7^{\circ} \mathrm{C}$, latent heat is the main factor influencing the net heat flux, espe- 

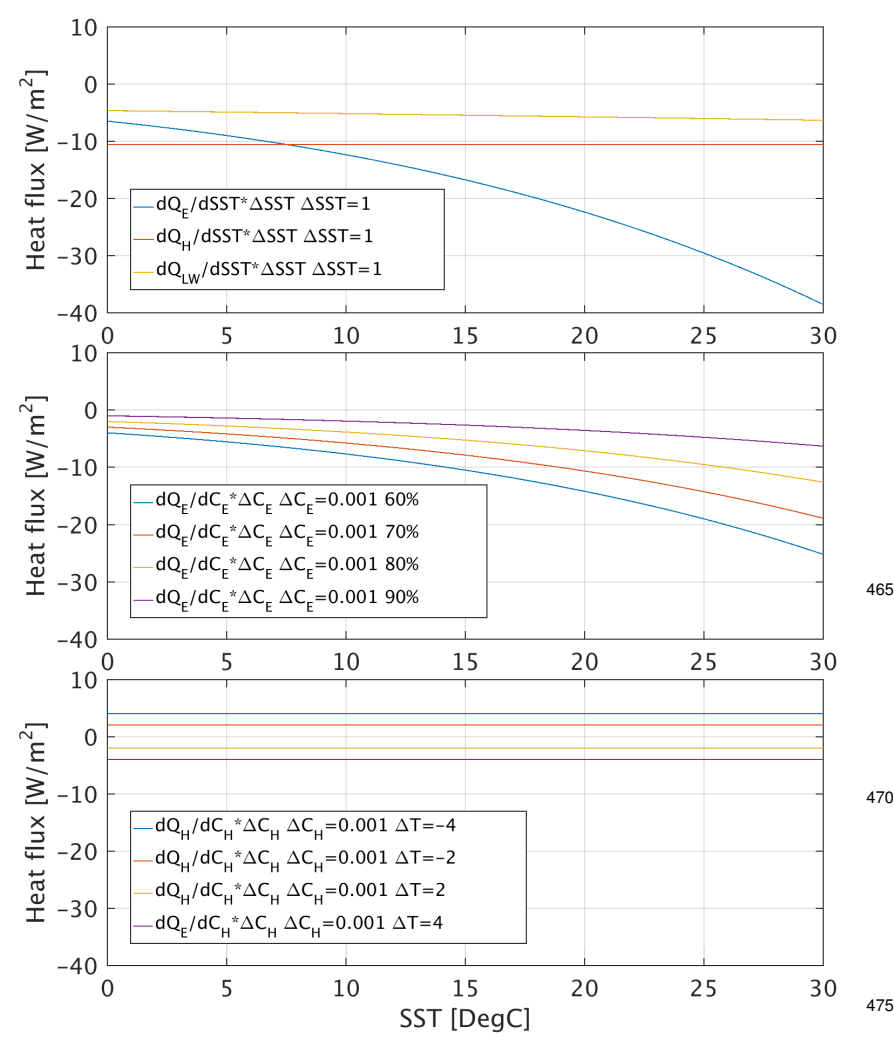

Figure 5: The effect of the SST and the exchange coefficients on the resulting heat flux. The upper panel shows the derivative of the latent heat, sensible heat, and long wave radiation with respect to change in the SST (multiplied by $\triangle S S T=1$ to have the same units in the three panels; and using 1992 global $_{480}$ and time average exchange coefficients values, $C_{E}=0.0120$ and $C_{H}=0.0105$ ). The middle panel shows the derivative of the latent heat with respect to the latent heat exchange coefficient for four different $2 m$ relative humidity percentages typical above the ocean. The lower panel shows the derivative of the sensible heat with respect to the sensible heat exchange coefficient for four typical temperature differences ( $2 \mathrm{~m}$ temperature minus SST). Units in $\mathrm{W} \mathrm{m}^{-2}$

cially for the low relative humidity case, in which a small positive change of the heat exchange coefficient can have a strong influence on latent heat. The sensible heat and long wave ra-490 diation seem to have a secondary effect because of the small change in the heat flux they produce but they both can become predominant at cold SST. Since both magnitudes are comparable (the blue line in the upper panel and the four lines in the middle panel of Figure 5), it can be concluded that the latent heat flux change between the MERRA-2-flux and MERRA-2- 495 state sensitivity experiments is controlled both by the change in SST and the change in the exchange coefficients.

Figure 5 furthermore reveals the reason why long wave radiation and sensible heat remain almost unchanged in the MERRA2-state run: their sensitivity to changes in SST is small relative ${ }_{500}$ to the sensitivity of latent heat. When SST declines due to low heat fluxes from MERRA-2 in the beginning of the MERRA2-state run, the latent heat feedback is the most efficient way to increase and compensate for the low heat flux compared to ECCO-v4.

Interestingly, if the bulk formulae and the albedo $\left(d Q_{S W}\right)$ of MERRA-2 and ECCO-v4 were the same, one could define a relaxation coefficient:

$$
\frac{1}{R} \equiv-\left(\frac{d Q_{E}}{d S S T}+\frac{d Q_{H}}{d S S T}+\frac{d Q_{L W}}{d S S T}\right) /\left(\rho \cdot C_{P} \cdot \Delta z\right)
$$

where $\rho$ is the density of the upper level of the ocean model and $\Delta z$ is its depth. This can be used to interpret the bulk formulae as a relaxation to MERRA-2 SST with spatially and temporallydependent relaxation time scale $R$. The resulting flux is

$$
F=\frac{Q_{n e t}^{M E R R A-2}}{\rho \cdot C_{P} \cdot \Delta z}-\frac{1}{R} \cdot\left(S S T-S S T_{m}\right),
$$

which is similar to the formulations of Haney (1971) and Barnier 5 et al. (1995), but with 6-hourly as opposed to monthly atmospheric forcing.

The similarity of MERRA-2-state SST and MERRA-2 SST is therefore not a coincidence. As long as the two bulk formulae of the atmospheric model and the ocean model are similar, the ocean model will relax the simulated SST to the SST used in the atmospheric model when the ocean model is forced with atmospheric state variables. The fluxes of the atmospheric model (which are determined by the SST) are replicated by the ocean model when the SST used in the atmospheric model is equal to the SST simulated by the ocean model. If the simulated SST tends to be greater (smaller) than the SST used in the atmospheric model, the bulk formulae and the long wave radiation feedback will tend to increase (decrease) the upward heat flux and this will relax the ocean model SST back to the atmospheric model SST.

In MERRA-2-state we allow for some of the feedbacks between the ocean and the atmosphere to be active, unlike in MERRA-2-flux. It therefore represents a coupled DA system that is less constrained (more active feedbacks) than the system represented in the MERRA-2 flux experiment. In this case, the latent heat compensates for the heat flux imbalance and causes large changes to the water cycle. In an actual coupled DA system these errors in the water cycle may be reduced by the adjustment of the surface specific humidity and precipitation, and so MERRA-2 state represents an amplification of the propagation of errors that will propagate to the water cycle.

\subsection{MITgcm forced with MERRA-2 turbulent fluxes}

In the MERRA-2-state experiment, the latent heat flux exhibited a large and unrealistic change from the MERRA-2-flux experiment. These results led us to test a third forcing configuration, called MERRA-2-turb, where turbulent fluxes are prescribed and long wave radiation is the only interactive heat flux component.

Figure 6 shows the results of this third (MERRA-2-turb) forcing configuration. The net heat flux is smaller than in MERRA2-state and larger than in MERRA-2-flux. The mean SST is also in between the MERRA-2-flux and MERRA-2-state values. The strong temperature reduction in the Central Pacific, the Maritime Continent, and the Bay of Bengal seen in the MERRA-2-flux experiment is mitigated and the temperature distribution gets closer to ECCO-v4 and MERRA-2 SSTs. 


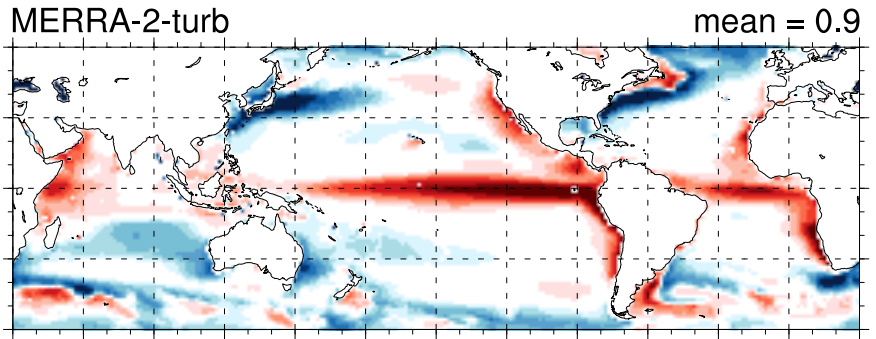

Net heat flux $\left[\mathrm{W} / \mathrm{m}^{\wedge} 2\right]$

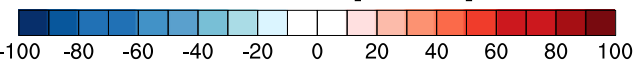

MERRA-2-turb - MERRA-2

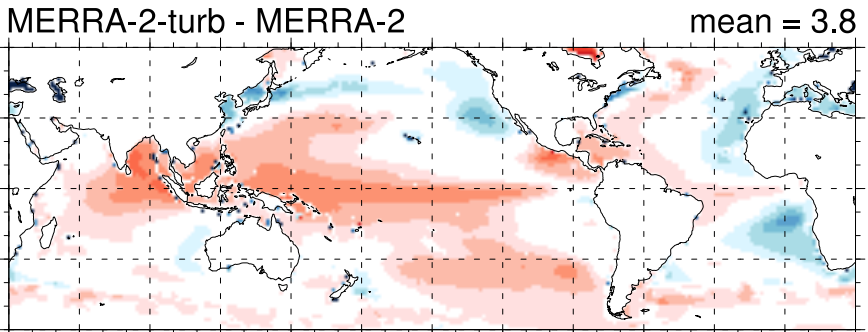

Net heat flux $\left[\mathrm{W} / \mathrm{m}^{\wedge} 2\right]$
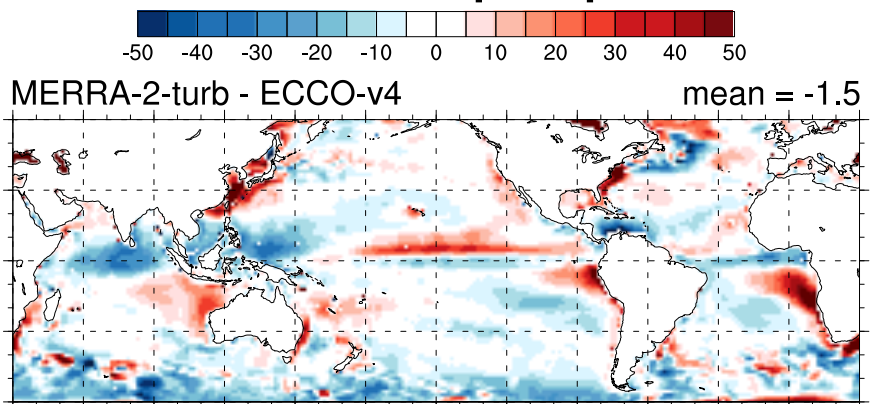

Net heat flux $\left[\mathrm{W} / \mathrm{m}^{\wedge} 2\right]$

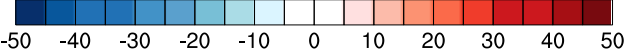

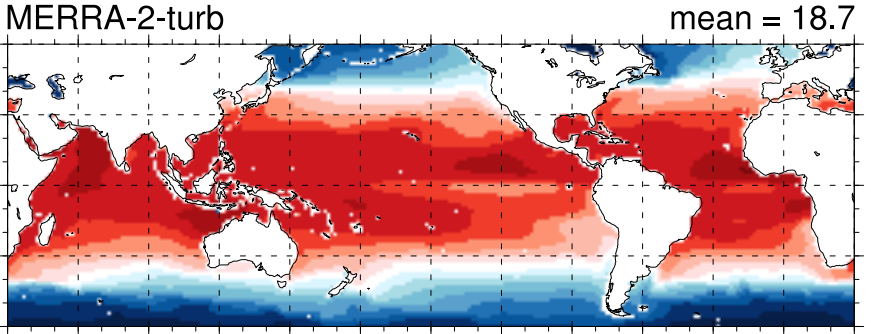
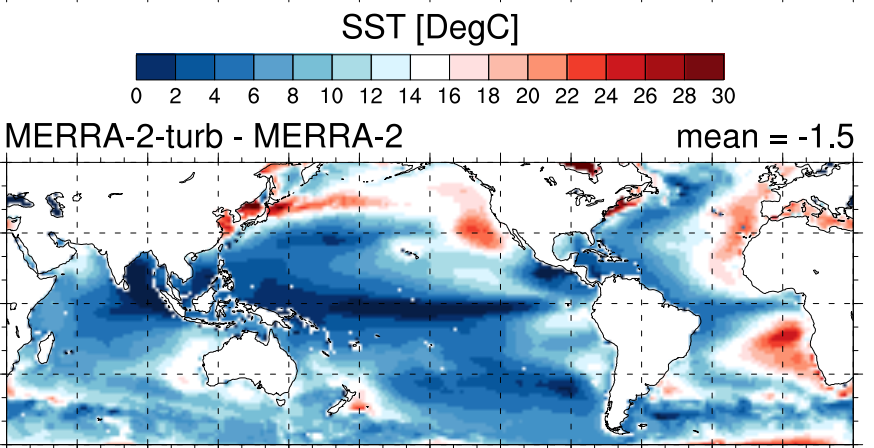

SST [DegC]
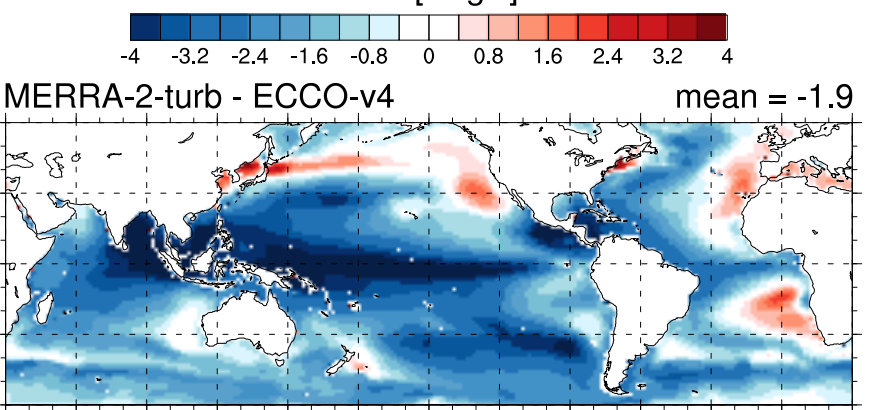

SST [DegC]

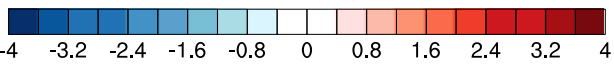

Figure 6: MERRA-2-turb spatial distribution of 20-year average of net total heat flux (in $\mathrm{W} \mathrm{m}^{-2}$ ); and SST (in ${ }^{\circ} \mathrm{C}$ ). The first column shows MERRA-2-turb, the second column shows MERRA-2-turb minus the original MERRA-2, and the third column shows MERRA-2-turb minus ECCO-v4.

In this experiment, the latent heat and sensible heat are not 525 interactive. They are identical to those in MERRA-2-flux (Figure 7). The net short wave radiation is not interactive but has about 2\% difference from MERRA-2 (as in the MERRA-2state case due to differences between MITgcm and MERRA-2 surface albedo). The net long wave radiation is closer to the ${ }_{530}$ observation-based products (Figure A.3).

In MERRA-2-turb, the SST was decreased by $\approx 1.9^{\circ} \mathrm{C}$ compared to ECCO-v4 (Figure 6, third row, right) in response to the negative heat flux of MERRA-2. The emitted long wave radiation was reduced to offset some of the negative heat flux, but since the turbulent heat flux is not interactive and since ${ }_{535}$ the sensitivity of the long wave radiation to changes in SST is smaller than for latent heat, the change in SST and emitted long wave is larger than in MERRA-2-state. Table 3 summarizes the global 20-year-average properties of the three experiments and of ECCO-v4.

The MERRA-2-turb experiment lies between the MERRA- 2-flux and MERRA-2-state experiments in terms of the active feedbacks. Here, we constrained the turbulent fluxes based on observations, but we are also weakly relaxing to observed SST (since only the last term in the brackets in the right-hand side of Equation 5 is active). This result may reflect a "compromise" state between the ocean and the atmosphere in a coupled DA system.

\subsection{Relaxation to prescribed SST}

It is common in different data assimilation systems to relax the ocean SST to prescribed values in order to prevent the model from drift to its own climatology. CFSR, for example, uses relaxation in their coupled data assimilation procedure. Our suggested methodology can be used to investigate the potential effect of SST relaxation on a coupled system.

We performed a set of experiments in which MITgcm ocean was forced with MERRA-2 fluxes and relaxed to observed SST 


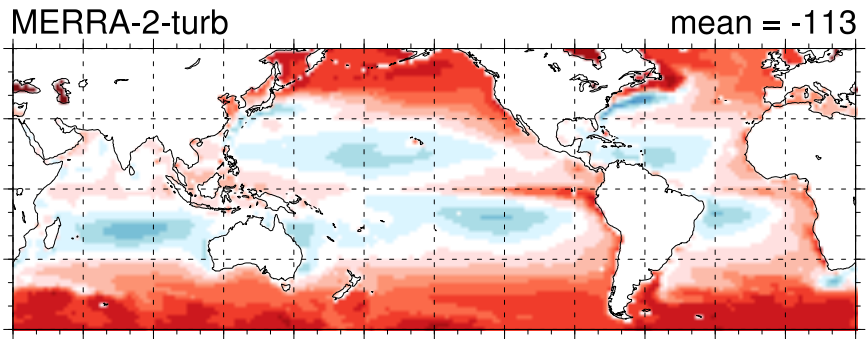

Latent Heat $\left[\mathrm{W} / \mathrm{m}^{\wedge} 2\right]$
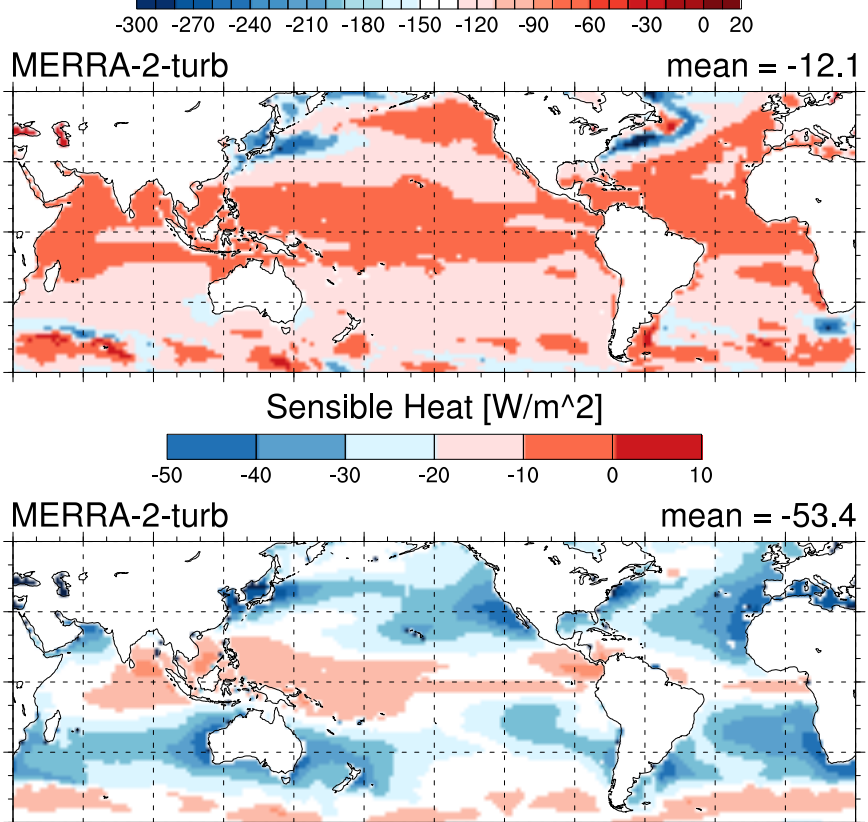

Net long wave radiation $\left[\mathrm{W} / \mathrm{m}^{\wedge} 2\right]$
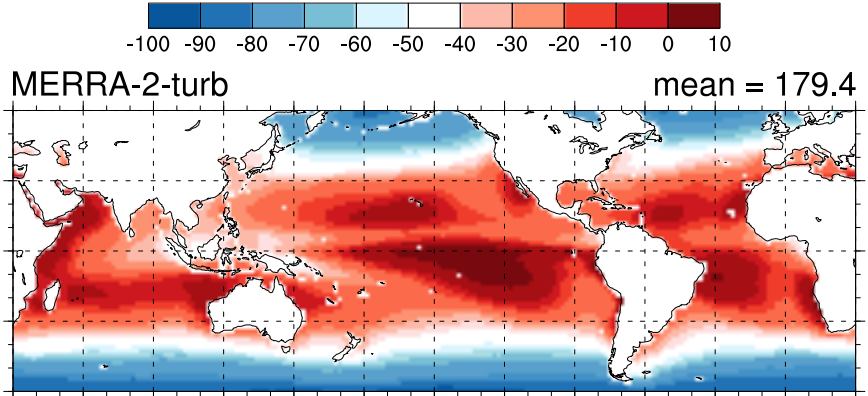

Net short wave radiation $\left[\mathrm{W} / \mathrm{m}^{\wedge} 2\right]$

$\begin{array}{llllllllllll}40 & 60 & 80 & 100 & 120 & 140 & 160 & 180 & 200 & 220 & 240 & 260\end{array}$

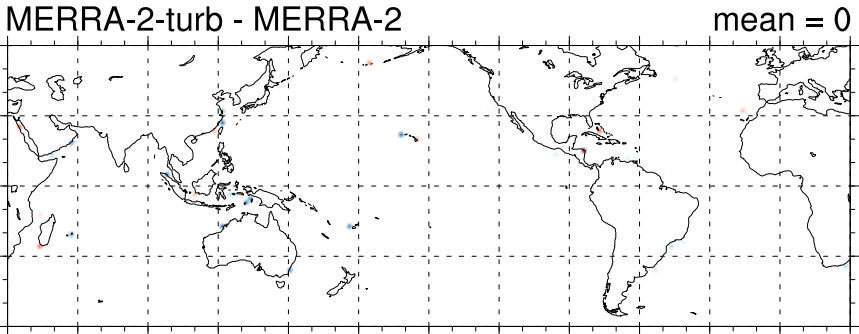

Latent Heat $\left[\mathrm{W} / \mathrm{m}^{\wedge} 2\right]$
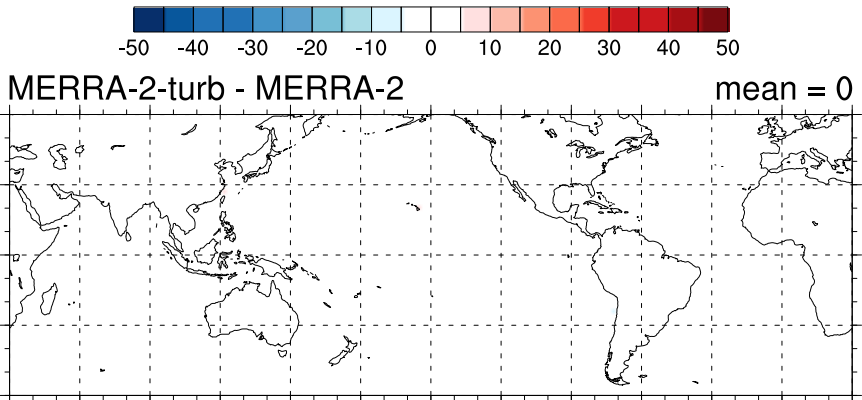

Sensible Heat [W/m^2]
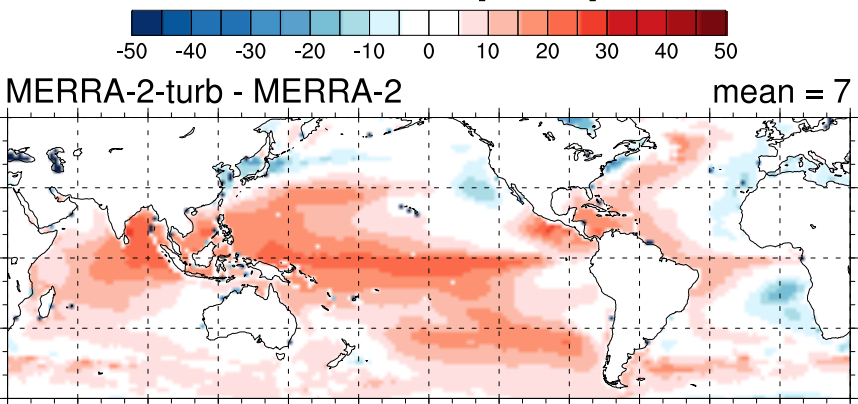

Net long wave radiation $\left[\mathrm{W} / \mathrm{m}^{\wedge} 2\right]$
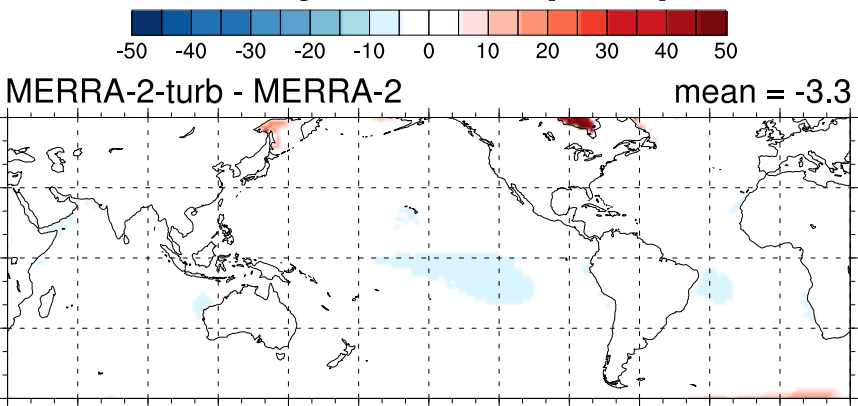

Net short wave radiation $\left[\mathrm{W} / \mathrm{m}^{\wedge} 2\right]$

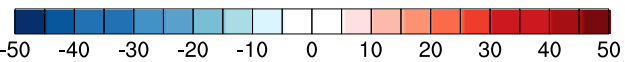

Figure 7: MERRA-2-turb spatial distribution of 20-year average of latent heat, sensible heat, net long wave radiation, and net short wave radiation (in $\mathrm{W} \mathrm{m}^{-2}$ ); and SST (in ${ }^{\circ} \mathrm{C}$ ). The first column shows MERRA-2-turb fluxes and the second column shows MERRA-2-turb minus the original MERRA-2 fluxes.

with relaxation time scales ranging from 12 hours to one year .550 Figures B.1,B.2 and B.3, which are the equivalent to figures 3 and 6 , show the outcome from three of these experiments (relaxation time scale: $0.5,180$ and 360 days, piston velocities: $20,1 / 18$ and $1 / 36 \mathrm{~m} \mathrm{day}^{-1}$ ).

These figures do show quantitatively different results but ${ }_{555}$ in terms of the feedbacks they are qualitatively similar to the feedbacks discussed in the paper. This is because the latent heat, sensible heat and long wave feedbacks are, to some extent, equivalent to a relaxation to SST in the sense that they relax the ocean model SST to the observed SST (as seen by MERRA2 reanalysis). This finding was demonstrated in Equations 5 and 6 which show that the feedbacks act as spatially dependent relaxation time scales. These additional experiments help to quantify the relaxation time scale implied by the different feedbacks. The strong relaxation experiment is more similar to 
the MERRA-2-state experiment (or the original ECCO-v4 solution) and an infinite relaxation time scale will approach by

\subsection{Time series}

Figure 8 shows the time evolution of the global and annual mean SST for MERRA-2-flux, MERRA-2-turb, MERRA2-state, ECCO-v4, MERRA-2 and the three relaxation experiments. It reveals that the SST in MERRA-2-flux after 20 years remains far from an equilibrated state, as it keeps decreasing at ${ }^{600}$ a near-steady rate of $\approx 0.25^{\circ} \mathrm{C}$ year $^{-1}$. The SST in MERRA2-turb also drifts during the first 15 years but then appears to reach a quasi-balance at $\approx 2.5^{\circ} \mathrm{C}$ below ECCO-v4. The SST in

570 MERRA-2-state only drifts during the first year by $\approx 0.25^{\circ} \mathrm{C}$ less than ECCO-v4 and then converges to the MERRA-2 SST. This reflects a relaxation to SST at the expense of the water cycle (Figure 9).

As we have seen in Figure 5, the latent heat has the largest feedback on the SST. Therefore, MERRA-2-state, which includes an interactive latent heat, is the first to converge to a quasi-equilibrium state (small $R$ ). MERRA-2-turb has only the interactive emitted long wave radiation and since this feedback is weaker than the latent heat feedback (larger $R$ ), this experiment has a cooler SST and a longer equilibration time scale.

Figure 8 shows that, in terms of the SST, half day relaxation is similar to MERRA-2-state (or original ECCO-v4) and 180 days relaxation is similar to MERRA-2-turb. 360 days relaxation is approaching MERRA-2-flux as expected. The SSS response shown in figure 9 behaves differently since the relaxation does not change the ocean total salinity as in MERRA2 -state but it does change the circulation of the ocean and that results different surface salinity compared to MERRA-2-flux.

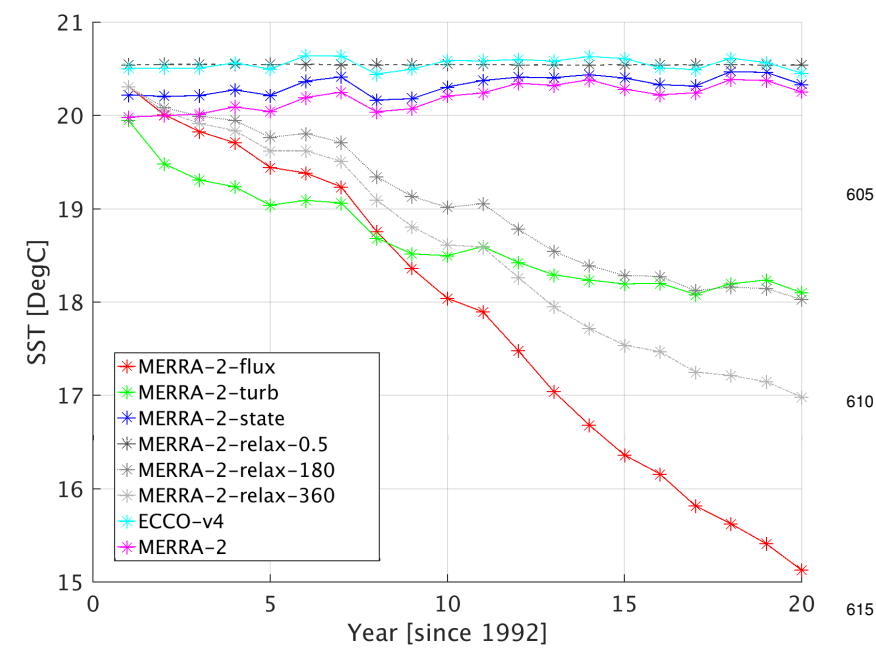

Figure 8: The time evolution of the annual mean SST $\left(60^{\circ} \mathrm{S}-60^{\circ} \mathrm{N}\right)$ for the six sensitivity experiments, ECCO-v4 and MERRA-2 (in ${ }^{\circ} \mathrm{C}$ ).

The effect of the link between evaporation and latent heat becomes clear when considering the evolution of sea surface salinity (SSS; Figure 9). In MERRA-2-state, the interactive latent heat reduced the evaporation and therefore increased the net fresh water flux to the ocean. This resulted in a large SSS drift in MERRA-2-state whereas ECCO-v4, MERRA-2-flux, and MERRA-2-turb all show relatively small SSS changes compared with MERRA-2-state. SSS drift in MERRA-2-state also had implications for the annual overturning circulation by making it weaker compared to MERRA-2-flux and MERRA-2-turb (not shown). The SSS in the relaxation experiments is more similar to MERRA-2-flux since the total ocean salinity in the relaxation experiments is the same. The change in SSS is due to a difference in the ocean circulation.

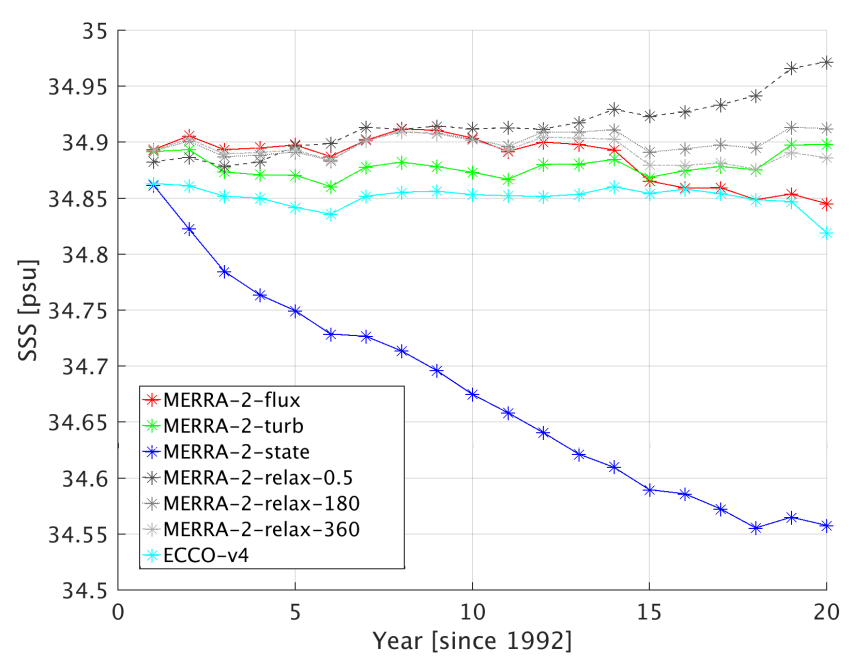

Figure 9: The time evolution of the annual mean $\operatorname{SSS}\left(60^{\circ} \mathrm{S}-60^{\circ} \mathrm{N}\right)$ for six sensitivity experiments, ECCO-v4 and MERRA-2 (in psu).

\section{Model-data misfit}

The ECCO-v4 solution was obtained via an optimization of 1992 initial conditions, surface boundary conditions, and internal ocean model parameters that minimized the cost function defined in Forget et al. (2015a). The total cost function is a measure of model-data misfits that involves many in-situ observations and gridded data sets. In Figure 10 we use the globally-averaged Argo temperature and salinity cost function terms as a measure of model-data misfits below the sea surface to compare our various solutions. MERRA-2-state derived temperature performed better than the two other forcing methods, whereas MERRA-2-turb derived salinity had the smallest cost, albeit close to that from MERRA-2-state. Near the surface, MERRA-2-turb salinity is clearly more realistic than in MERRA-2-state but the situation reverses at depth (Figure 11).

In Figure 10, we also added an experiment called "MERRA2-prcorr", identical to MERRA-2-state but with a corrected precipitation product based on the Global Precipitation Climatology Project (GPCP). The MERRA-2 corrected precipitation product uses GPCP precipitation but poleward of $\pm 42.5^{\circ}$ it tapers back to MERRA-2. It is completely MERRA-2 precipitation 
Table 3: Global 20-year properties of MERRA-2-flux, MERRA-2-state, and MERRA-2-turb (note that the average values in previous figures over each panel were not global but for $60^{\circ} \mathrm{S}-60^{\circ} \mathrm{N}$ domain). Values in parenthesis (in the three relaxation experiments) represent the net heat flux including the artificial relaxation flux term

\begin{tabular}{llllllll}
\hline \hline & ECCO-v4 & $\begin{array}{l}\text { MERRA-2- } \\
\text { flux }\end{array}$ & $\begin{array}{l}\text { MERRA-2- } \\
\text { state }\end{array}$ & $\begin{array}{l}\text { MERRA-2- } \\
\text { turb }\end{array}$ & $\begin{array}{l}\text { MERRA-2- } \\
\text { relax-0.5 }\end{array}$ & $\begin{array}{l}\text { MERRA-2- } \\
\text { relax-90 }\end{array}$ & $\begin{array}{l}\text { MERRA-2- } \\
\text { relax-360 }\end{array}$ \\
\hline $\begin{array}{l}\text { Global average heat } \\
\text { flux [W m }\end{array}{ }^{-2}$ ] & 0.3 & -4.6 & 1.0 & -1.1 & $-4.6(2.0)$ & $-4.6(-1.0)$ & $-4.6(-2.2)$ \\
\hline $\begin{array}{l}\text { Global average SST } \\
{\left[{ }^{\circ} \mathrm{C}\right]}\end{array}$ & 18.5 & 16.0 & 18.2 & 16.8 & 18.5 & 17.1 & 16.7 \\
\hline $\begin{array}{l}\text { Total fresh water flux } \\
{\left[\mathrm{mm} \text { year }{ }^{-1} \text { ] }\right.}\end{array}$ & 2.8 & -52 & 82 & -52 & -52 & -52 & -52 \\
\hline $\begin{array}{l}\text { Global average SSS } \\
{[\mathrm{psu}]}\end{array}$ & 34.709 & 34.732 & 34.537 & 34.718 & 34.744 & 34.742 & 34.738 \\
\hline
\end{tabular}

poleward $\pm 62.5^{\circ}$ Bosilovich et al. (2015a). MERRA-2-prcorr had the best global mean sea level relative to ECCO-v4, a $-0.3 m_{66}$ bias, but in terms of the salinity cost function, it did not manage to reduce cost relative to MERRA-2-state and MERRA2-turb. In other words, although the corrected precipitation in MERRA-2-prcorr produces a global-mean sea level closer to observations, it distorted the spatial distribution of the total water cycle.

Subsurface temperature errors in MERRA-2-turb and MERRA2-flux are directly related to their relatively large SST drift as compared to MERRA-2-state. The SST in MERRA-2-state is which differs slightly from ECCO-v4 SST but has similar spatial variability. Therefore, temperature errors related to the net ${ }_{675}$ heat flux are not substantial in MERRA-2-state as compared to MERRA-2-turb and MERRA-2-flux. Salinity errors can emerge temperature errors affecting ocean circulation and such dynamical effects may be revealed by the collocation of temperature and salinity misfits seen in MERRA-2-turb and MERRA2-flux at depth (Figure 11). However, since there is effectively no feedback restoring to observations in the water cycle, siznotably shows a large surface salinity drift as a result of increased latent heat flux that is coupled to evaporation via the bulk formulae (Figure 9). Improved SSS constraints emerging from dedicated satellite missions, such as Aquarius, are beginpartially alleviate the lack of active feedback mechanisms.

Although MERRA-2-state is closer to temperature observa- ${ }_{690}$ tions than MERRA-2-turb, the connection to the water cycle through latent heat flux thus appears problematic. MERRA-2rb, which only includes the black body radiation feedback therefore provides a valuable alternative that could, for example, serve as a first guess for ocean state estimation purposes. Figure 11 supports this statement when compared with Figure 1 in Forget et al. (2015b) and Figure 10 in Forget et al. (2015a) by showing that the MERRA-2-turb solution is in the range of the previous ECCO solutions. MERRA-2-relax-0.5 experiment which has a strong relaxation to observed SST, was already shown to behave similarly to MERRA-2-state without having the connection to the water cycle. Compared to MERRA-2state, this experiment has smaller errors in terms of the cost (Figure 10) but it shows degradation at depth (Figure B.4).

\section{Summary and discussion}

In this study, we evaluated, relative to the ECCO-v4 ocean state estimate, a series of ocean-only simulations using different forcing methods and atmospheric fields from the MERRA-2 reanalysis. ECCO-v4 represents a "best linear unbiased estimate" from an ocean state estimation perspective whereas MERRA2 represents a "best linear unbiased estimate" (Wunsch, 2006) from an atmospheric reanalysis perspective.

Direct comparison of MERRA-2 and ECCO-v4 revealed the total net heat flux to the ocean in MERRA-2 to be negative and its magnitude unrealistically large compared to what is known in terms of the Earth's global energy imbalance (e.g., Allan et al., 2014; Johnson et al., 2016), while in ECCO-v4 it was positive. The global mean difference between the two exceeds $5 \mathrm{~W} \mathrm{~m}^{-2}$. When the MITgcm in its ECCO-v4 configuration was forced with MERRA-2 fluxes directly (the MERRA-2-flux experiment), the negative heat flux resulted in a near-steady sea surface temperature decline of $\approx 0.25^{\circ} \mathrm{C}_{\text {year }}{ }^{-1}$.

Forcing MITgcm with MERRA-2 state variables (the MERRA2-state experiment) and computing turbulent fluxes with bulk formulae reduced this drift and effectively restored sea surface temperatures to those used in MERRA-2. The SST of the MERRA2-state experiment converged to the SST of the MERRA-2 forcing data because of the strong latent-heat feedback associated with the bulk formulae. This approach, however, dramatically reduced evaporation, which resulted in an increase of sea level by an unrealistic $2.7 \mathrm{~m}$ over 20 years, which in reality (i.e., in a coupled system) would be, at least in part, compensated by increased precipitation and runoff. MERRA-2-state also suffered from SSS drift and large circulation changes compared to MERRA-2-flux and MERRA-2-turb. The lower net long wave radiation in MERRA-2 was indeed artificially compensated via latent heat fluxes in MERRA-2-state because this flux component is most sensitive to changes in SST. 


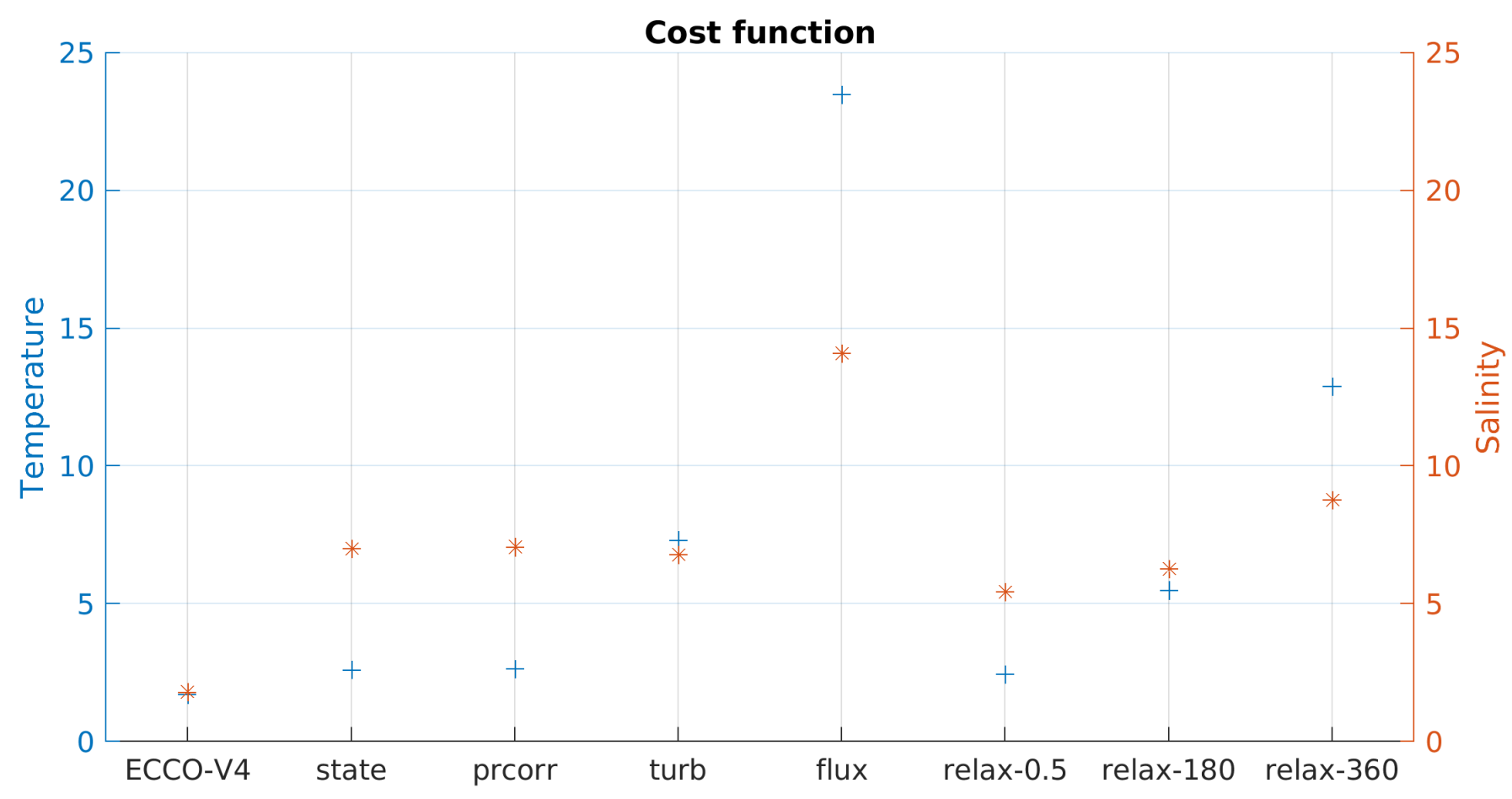

Figure 10: The global ECCO-v4 cost function for temperature (in ${ }^{\circ} \mathrm{C}$ ) and salinity (in psu).

Another experiment was conducted, in which turbulent fluxeso were prescribed but the long wave radiation was interactive (the MERRA-2-turb experiment). Although this method resulted in larger temperature errors than in MERRA-2-state, it has a better physical justification in terms of the water budget, i.e., it does not change the water balance unrealistically. The MERRA-2-735 turb configuration was shown to behave as though it has a relaxation term towards the SST of the forcing data imposed, but with a longer time scale of relaxation than is implied in the MERRA-2-state experiment because it is driven solely by the upward long wave radiation responding to ocean SST variations 740 (unlike the MERRA-2 state experiment, in which the latent heat and sensible heat flux feedbacks are also active). This experiment had larger temperature errors but the unchanged latent heat flux resulted in reduced salinity errors. An attempt to correct precipitation errors using GPCP observations was also pre-745 sented (the MERRA-2-prcorr experiment), but it did not generally result in smaller ocean state errors.

The results of this study indicate that, for some ocean modeling applications, the traditional surface forcing with atmospheric state variables and bulk formulae may not be optimal.750 It would be interesting to carry out forced ocean-model intercomparisons using the MERRA-2-turb approach. We expect results to differ substantially from those obtained using atmospheric state variables and bulk formulae (e.g., Danabasoglu et al., 2014). A combination of MERRA-2-turb forcing ap-755 proach together with more balanced atmospheric reanalysis (e.g., CORE-II), or an atmospheric state obtained from coupled atmosphero ocean data assimilation may, in the future, provide a more ac- curate product to force ocean models.

This study is the first step of a project that aims to obtain an improved reanalysis by combining ECCO-v4 and MERRA2 modeling and data assimilation methods toward a physically consistent, property-conserving coupled ocean-atmosphere analysis. In this step, we forced the MITgcm ocean model with surface boundary conditions that involve a range of active feedbacks. In each of the three sensitivity experiments, we found that the errors in the atmospheric forcing propagated to different components of the ocean model and we anticipate that these errors are amplifications of errors one may encounter in a coupled ocean-atmosphere DA system. The "flavor" of the DA will determine the character of these errors.

In real coupled DA systems, unlike our ocean-only analogs, no feedbacks are totally eliminated, instead they are damped by the atmospheric and ocean analysis. The coupled CFSR reanalysis (Saha et al., 2010), for example, shows a large net heat flux imbalance (Balmaseda et al., 2015; Valdivieso et al., 2017) of $\approx 12.5 \mathrm{~W} \mathrm{~m}^{-2}$ over a 17 -year period. The relaxation to SST requires a large change to correct the error and prevent substantial SST increase (Wang et al., 2011). This large SST correction damped the air-sea feedbacks. The implication for CFSR from our experiments lies in the character of the resulting fields (high heat flux imbalance and small effect on SST), not in any similarity to the architecture or configuration. Currently, the feedbacks in CFSR may be overactive because of the strong relaxation to observed SST (in analogy with the MERRA-2-state rer MERRA-2-relax-0.5 configurations). Although the SST in CFSR is close to observed values, the net heat flux to the ocean 

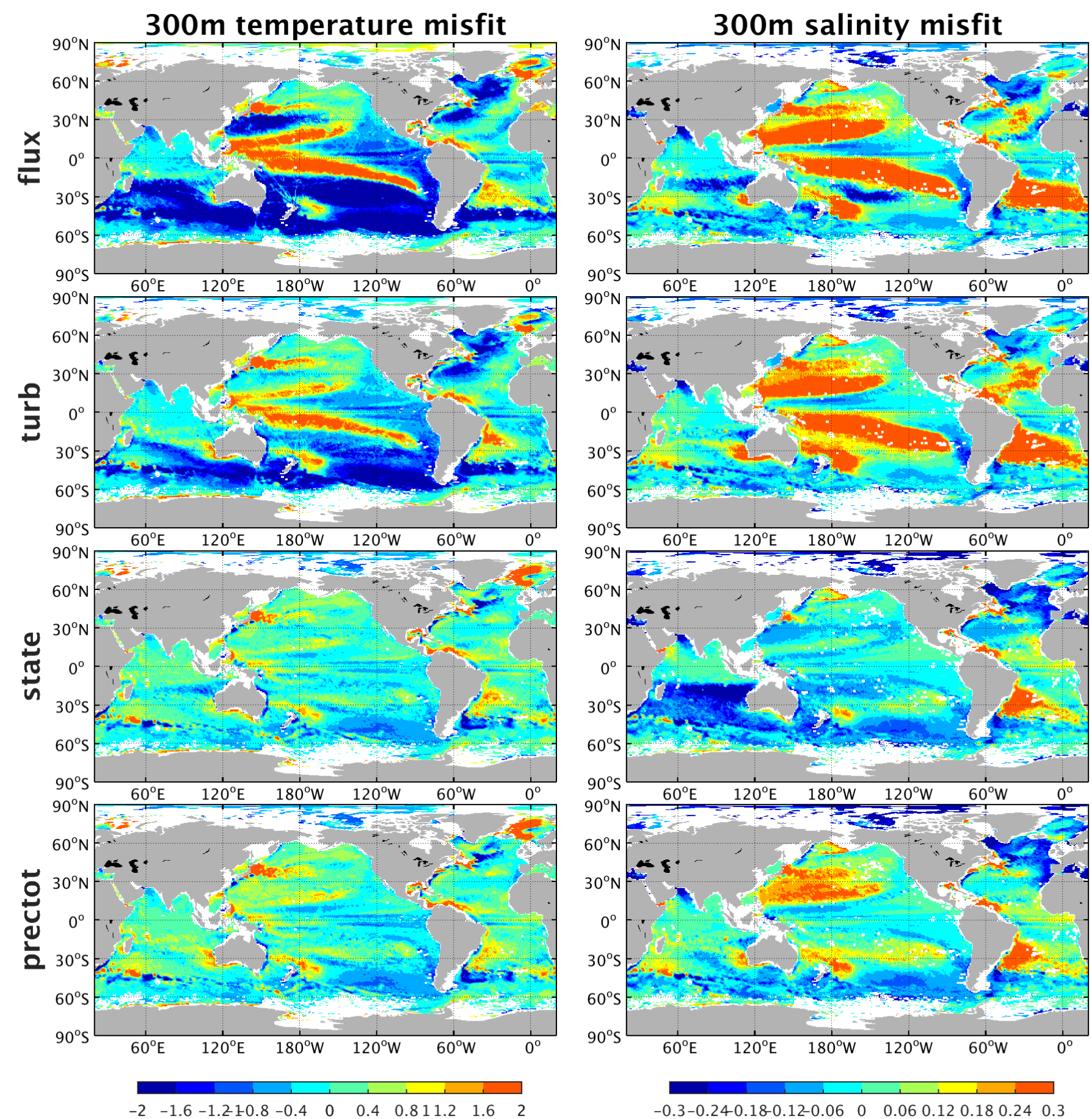

$-0.3-0.24-0.18-0.12-0.06 \quad 0 \quad 0.060 .120 .180 .24 \quad 0.3$

Figure 11: Time mean misfit (model-data) for in situ profiles at $300 \mathrm{~m}$ for $\mathrm{T}$ (left; in ${ }^{\circ} \mathrm{C}$ ) and $\mathrm{S}$ (right; in psu).

is highly imbalanced. Without the SST relaxation term that is included in CFSR, one may speculate that CFSR would be more similar to the MERRA-2-flux or MERRA-2-turb sensitivity experiments. A similarity in character to the MERRA-2turb experiment would suggest an underactive sensible and la-770 tent heat flux feedback in CFSR. A similarity to MERRA-2-flux would suggest an underactive long-wave feedback in the CFSR system, in addition to underactive latent and sensible heat flux feedbacks.

The investigation of air-sea flux errors in the uncoupled components of the model (as was done in Section 3.1) can help coupled DA groups anticipate errors in the coupled version of the system. A set of experiments similar to what was done in Section 3.2 may help identify systematic errors in the coupled 
model and may provide guidance for the development of future coupled DA systems in the future.

\section{Appendix A. Comparisons with observation-based products 25}

Figure A.1 shows MERRA-2 latent heat flux together with observation-based products GSSTF (Chou et al., 2003) and OAFlux (Yu and Weller, 2007). MERRA-2 latent heat is on average lower than OAFlux. It is smaller than GSSTF in the low lati-8зо tudes and larger in mid-latitudes. OAFlux and GSSTF also have a large disagreement.

Figure A.2 shows MERRA-2 sensible heat flux together with observation-based products GSSTF (Chou et al., 2003)835 and OAFlux (Yu and Weller, 2007). MERRA-2 and observationbased products do not agree mainly in mid-latitudes and this also where the observation-based product do not agree with them selfs.

Figure A.3 shows MERRA-2 net long wave radiation flux together with observation-based products GEWEX-SRB (Chou et al., 2003) and OAFlux-ISCCP (Yu and Weller, 2007; Zhang et al., 2004). MERRA-2 net long wave radiation is lower than ${ }^{845}$ observation-based products. On average the two observationbased products agree but there are large local differences.

Figure A.4 shows MERRA-2 net short wave radiation flux together with observation-based products GEWEX-SRB (Stack ${ }^{850}$ house Jr et al., 2011) and OAFlux-ISCCP (Yu and Weller, 2007; Zhang et al., 2004). MERRA-2 short wave radiation is on average lower than observation-based products but the difference has also large spatial variability. OAFlux values are in general ${ }^{855}$ larger than SRB.

Figure A.5 shows MERRA-2 downward surface radiation together with observation-based products GEWEX-SRB (Zhang et al., 2004) and CERES-EBAF (Rutan et al., 2015). MERRA-2 ${ }^{860}$ downward long wave radiation is lower than observation-based products which agree well with each other.

\section{Appendix B. Relaxation experiments}

Figure B.1 shows MERRA-2-flux with 0.5 day relaxation time scale. Figure B.2 shows MERRA-2-flux with 180 day relaxation time scale. Figure B.3 shows MERRA-2-flux with $360^{870}$ day relaxation time scale. Figure B.1 shows that the spatial distribution of net heat flux and SST in a half day relaxation is similar to MERRA-2-state (Figure 3) and the spatial distribution of 180 days relaxation (Figure B.2) is similar to MERRA-2-turb (Figure 6). Net heat flux and SST of the 360 days relaxation (Figure B.3) is approaching MERRA-2-flux as expected (Figures 1 and 2).

In addition, figure B. 4 shows the $300 \mathrm{~m} \mathrm{SST}$ and SSS misfit. Even the strong 0.5day relaxation show degradation of the SSS compared to MERRA-2-state experiment.

\section{Acknowledgments}

The research leading to these results has received funding from the NASA Modeling, Analysis, and Prediction (MAP). ${ }_{890}$
GF was supported by NASA award \#6937342 and Simons Fundation award \#549931.

\section{References}

Adcroft, A., Campin, J.M., 2004. Rescaled height coordinates for accurate representation of free-surface flows in ocean circulation models. Ocean Modelling 7, 269 - 284. doi:http://doi.org/10.1016/j.ocemod.2003.09.003.

Allan, R.P., Liu, C., Loeb, N.G., Palmer, M.D., Roberts, M., Smith, D., Vidale, P.L., 2014. Changes in global net radiative imbalance 19852012. Geophysical Research Letters 41, 5588-5597. doi:10.1002/2014GL060962.

Balmaseda, M., Hernandez, F., Storto, A., Palmer, M., Alves, O., Shi, L., Smith, G., Toyoda, T., Valdivieso, M., Barnier, B., Behringer, D., Boyer, T., Chang, Y.S., Chepurin, G., Ferry, N., Forget, G., Fujii, Y., Good, S., Guinehut, S., Haines, K., Ishikawa, Y., Keeley, S., Khl, A., Lee, T., Martin, M., Masina, S., Masuda, S., Meyssignac, B., Mogensen, K., Parent, L., Peterson, K., Tang, Y., Yin, Y., Vernieres, G., Wang, X., Waters, J., Wedd, R., Wang, O., Xue, Y., Chevallier, M., Lemieux, J.F., Dupont, F., Kuragano, T., Kamachi, M., Awaji, T., Caltabiano, A., Wilmer-Becker, K., Gaillard, F., 2015. The ocean reanalyses intercomparison project (ora-ip). Journal of Operational Oceanography 8, s80-s97. doi:10.1080/1755876X.2015.1022329.

Barnier, B., Siefridt, L., Marchesiello, P., 1995. Thermal forcing for a global ocean circulation model using a three-year climatology of ecmwf analyses. Journal of Marine Systems 6, 363 - 380. doi:http://dx.doi.org/10.1016/09247963(94)00034-9.

Bengtsson, L., 2010. The global atmospheric water cycle. Environmental Research Letters 5, 025202

Bloom, S.C., Takacs, L.L., da Silva, A.M., Ledvina, D., 1996. Data assimilation using incremental analysis updates. Monthly Weather Review 124, 1256 1271. doi:10.1175/1520-0493(1996)124;1256:DAUIAU $2.0 . C O ; 2$.

Bosilovich, M., Lucchesi, R., Suarez, M., 2015a. Merra-2: File specification .

Bosilovich, M.G., 2015. MERRA-2: Initial evaluation of the climate. National Aeronautics and Space Administration, Goddard Space Flight Center.

Bosilovich, M.G., Akella, S., Coy, L., Cullather, R., Draper, C., Gelaro, R., Kovach, R., Liu, Q., Molod, A. Norris, P., Wargan, K., Chao, W., Reichle, R., Takacs, L., Vikhliaev, Y., Bloom, S., Collow, A., Firth, S., Labow, G., Partyka, G., Pawson, S., Reale, O., Schubert, S.D., Suarez, M., 2015b. Merra-2: Initial evaluation of the climate. Technical Report Series on Global Modeling and Data Assimilation 43, 139pp.

Brassington, G., Martin, M., Tolman, H., Akella, S., Balmeseda, M., Chambers, C., Chassignet, E., Cummings, J., Drillet, Y., Jansen, P., Laloyaux, P., Lea, D., Mehra, A., Mirouze, I., Ritchie, H., Samson, G., Sandery, P., Smith, G., Suarez, M., Todling, R., 2015. Progress and challenges in short- to medium-range coupled prediction. Journal of Operational Oceanography 8, s239-s258. doi:10.1080/1755876X.2015.1049875.

Brodeau, L., Barnier, B., Treguier, A.M., Penduff, T., Gulev, S., 2010. An era40-based atmospheric forcing for global ocean circulation models. Ocean Modelling 31, 88 - 104. doi:https://doi.org/10.1016/j.ocemod.2009.10.005.

Campin, J.M., Adcroft, A., Hill, C., Marshall, J., 2004. Conservation of properties in a free-surface model. Ocean Modelling 6, 221-244.

Carton, J.A., Chepurin, G., Cao, X., 2000a. A simple ocean data assimilation analysis of the global upper ocean 195095. part ii: Results. Journal of Physical Oceanography 30, 311-326. doi:10.1175/15200485(2000)030;0311:ASODAA ¿2.0.CO;2.

Carton, J.A., Chepurin, G., Cao, X., Giese, B., 2000b. A simple ocean data assimilation analysis of the global upper ocean 195095. part i: Methodology. Journal of Physical Oceanography 30, 294-309. doi:10.1175/15200485(2000)030;0294:ASODAA i2.0.CO;2.

Chambers, D.P., Cazenave, A., Champollion, N., Dieng, H., Llovel, W., Forsberg, R., von Schuckmann, K., Wada, Y., 2017. Evaluation of the Global Mean Sea Level Budget between 1993 and 2014. Surveys in Geophysics 38, 309-327.

Chou, S.H., Nelkin, E., Ardizzone, J., Atlas, R.M., Shie, C.L., 2003. Surface turbulent heat and momentum fluxes over global oceans based on the goddard satellite retrievals, version 2 (gsstf2). Journal of Climate 16, 32563273. doi:10.1175/1520-0442(2003)016;3256:STHAMF $2.0 . C O ; 2$.

Danabasoglu, G., Yeager, S.G., Bailey, D., Behrens, E., Bentsen, M., Bi, D., Biastoch, A., Bning, C., Bozec, A., Canuto, V.M., Cassou, C., Chassignet, E., Coward, A.C., Danilov, S., Diansky, N., Drange, H., Farneti, R., Fernandez, E., Fogli, P.G., Forget, G., Fujii, Y., Griffies, S.M., Gusev, A., Heimbach, 

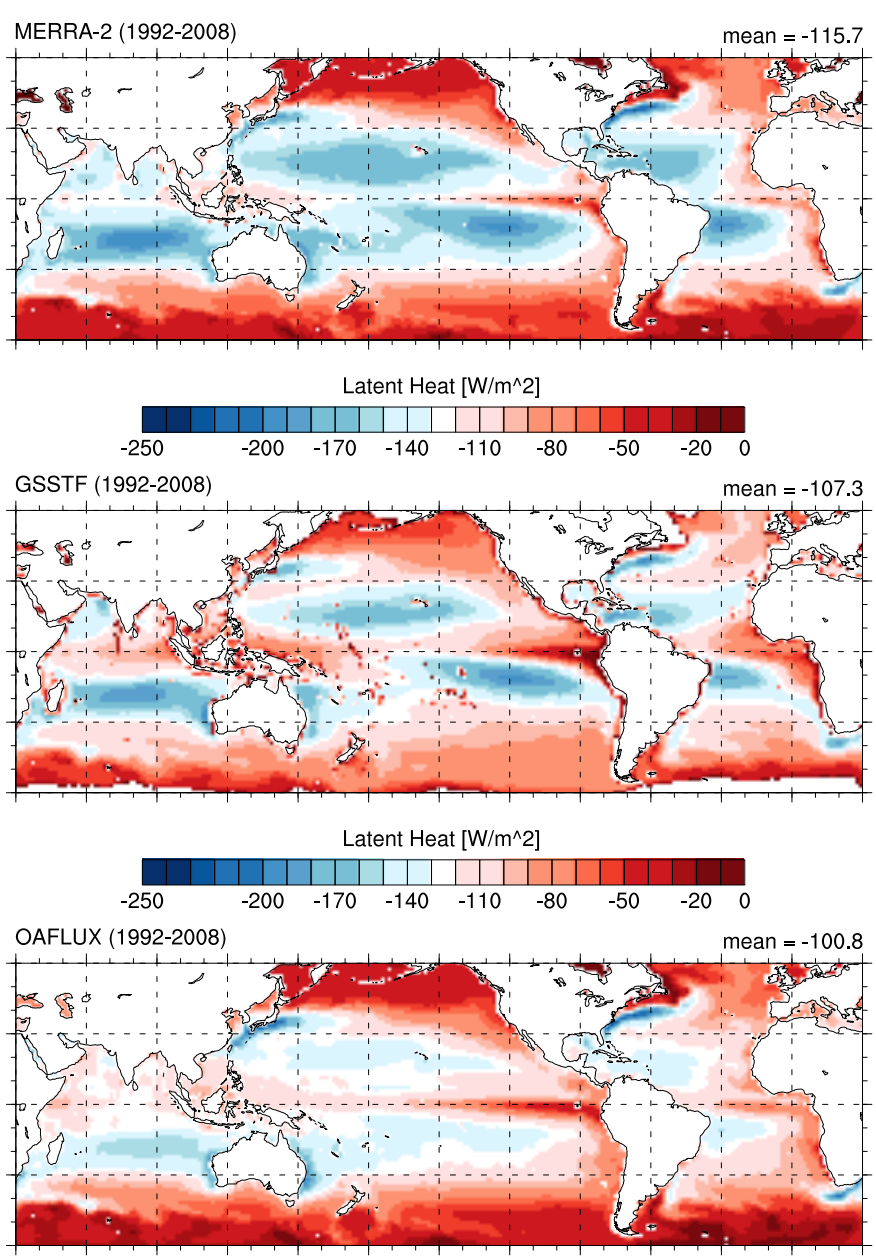

Latent Heat $\left[\mathrm{W} / \mathrm{m}^{\wedge} 2\right]$

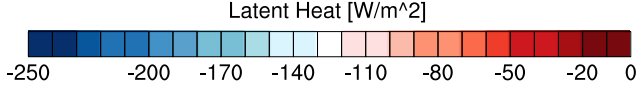

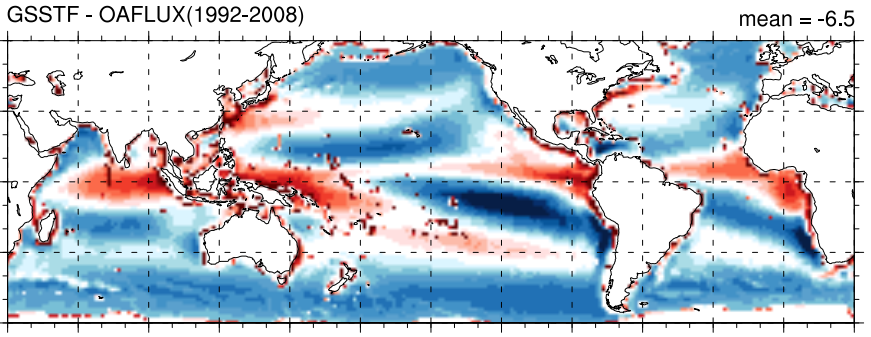
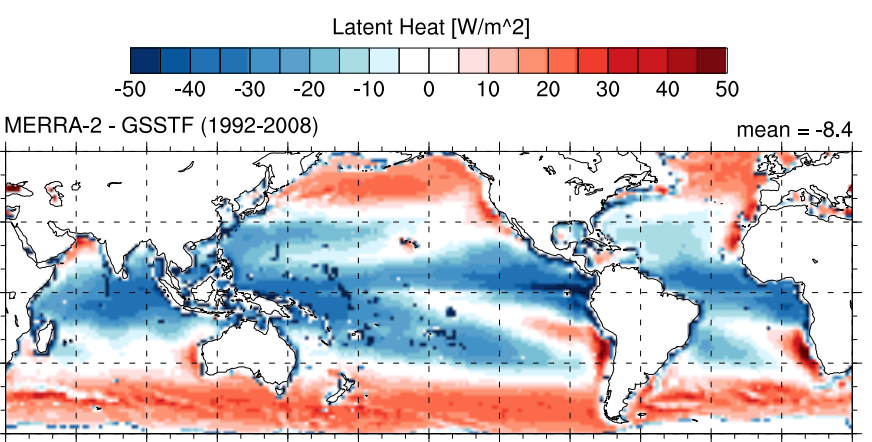

Latent Heat $\left[\mathrm{W} / \mathrm{m}^{\wedge} 2\right]$
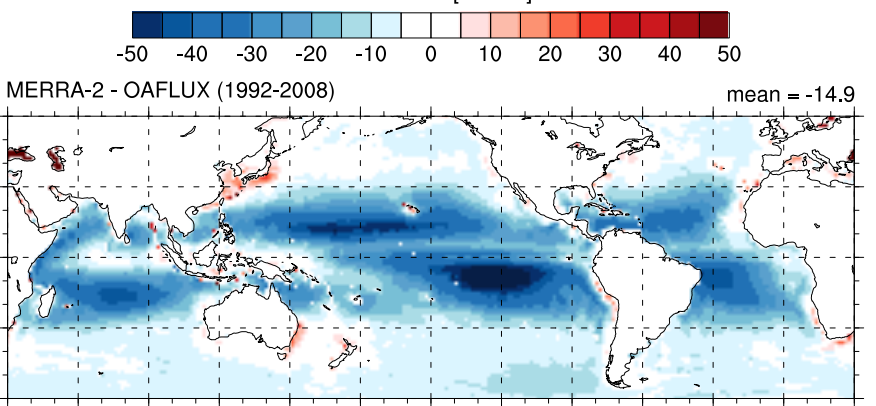

Latent Heat $\left[\mathrm{W} / \mathrm{m}^{\wedge} 2\right]$

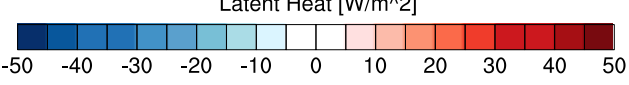

Figure A.1: Spatial distribution of mean latent heat (positive downward).

P., Howard, A., Jung, T., Kelley, M., Large, W.G., Leboissetier, A., Lu, J.,915 Madec, G., Marsland, S.J., Masina, S., Navarra, A., Nurser, A.G., Pirani, A., y Mlia, D.S., Samuels, B.L., Scheinert, M., Sidorenko, D., Treguier, A.M., Tsujino, H., Uotila, P., Valcke, S., Voldoire, A., Wang, Q., 2014. North atlantic simulations in coordinated ocean-ice reference experiments phase ii (core-ii). part i: Mean states. Ocean Modelling 73, 76 - 107.

Dee, D.P., Balmaseda, M., Balsamo, G., Engelen, R., Simmons, A.J., Thpaut, J.N., 2014. Toward a consistent reanalysis of the climate system. Bulletin of the American Meteorological Society 95, 1235-1248. doi:10.1175/BAMSD-13-00043.1.

Dee, D.P., Uppala, S.M., Simmons, A.J., Berrisford, P., Poli, P., Kobayashi, S.,925 Andrae, U., Balmaseda, M.A., Balsamo, G., Bauer, P., Bechtold, P., Beljaars, A.C.M., van de Berg, L., Bidlot, J., Bormann, N., Delsol, C., Dragani, R., Fuentes, M., Geer, A.J., Haimberger, L., Healy, S.B., Hersbach, H., Hlm, E.V., Isaksen, L., Kllberg, P., Khler, M., Matricardi, M., McNally, A.P., Monge-Sanz, B.M., Morcrette, J.J., Park, B.K., Peubey, C., de Rosnay, P.,930 Tavolato, C., Thpaut, J.N., Vitart, F., 2011. The era-interim reanalysis: configuration and performance of the data assimilation system. Quarterly Journal of the Royal Meteorological Society 137, 553-597. doi:10.1002/qj.828. mer, W., 2012. The operational sea surface temperature and sea ice 935 analysis (ostia) system. Remote Sensing of Environment 116, 140 158. doi:http://dx.doi.org/10.1016/j.rse.2010.10.017. advanced Along Track Scanning Radiometer(AATSR) Special Issue.

Fekete, B.M., Vrsmarty, C.J., Grabs, W., 2002. High-resolution fields of global runoff combining observed river discharge and simulated water balances. Global Biogeochemical Cycles 16, 15-1-15-10. doi:10.1029/1999GB001254.

Forget, G., 2016. gaelforget/ECCO_v4_r2: Initial release of ECCO v4 r2 model setup via github (v1.1). doi:10.5281/zenodo.225777.

Forget, G., Campin, J.M., Heimbach, P., Hill, C.N., Ponte, R.M., Wunsch, C., 2015a. Ecco version 4: an integrated framework for non-linear inverse modeling and global ocean state estimation. Geoscientific Model Development 8, 3071-3104. doi:10.5194/gmd-8-3071-2015.

Forget, G., Ferreira, D., Liang, X., 2015b. On the observability of turbulent transport rates by argo: supporting evidence from an inversion experiment. Ocean Science 11, 839-853. doi:10.5194/os-11-839-2015.

Forget, G., Ponte, R., 2015. The partition of regional sea level variability. Progress in Oceanography, 173-195doi:10.1016/j.pocean.2015.06.002.

Garfinkel, C.I., Molod, A.M., Oman, L.D., Song, I.S., 2011. Improvement of the geos-5 agcm upon updating the air-sea roughness parameterization. Geophysical Research Letters 38, n/a-n/a. doi:10.1029/2011GL048802. 118702. Gelaro, R., McCarty, W., Surez, M.J., Todling, R., Molod, A., Takacs, L., Randles, C., Darmenov, A., Bosilovich, M.G., Reichle, R., Wargan, K., Coy, L., Cullather, R., Draper, C., Akella, S., Buchard, V., Conaty, A., da Silva, A., Gu, W., Kim, G.K., Koster, R., Lucchesi, R., Merkova, D., Nielsen, J.E., Partyka, G., Pawson, S., Putman, W., Rienecker, M., Schubert, S.D., Sienkiewicz, M., Zhao, B., 2017. The modern-era retrospective analysis for 

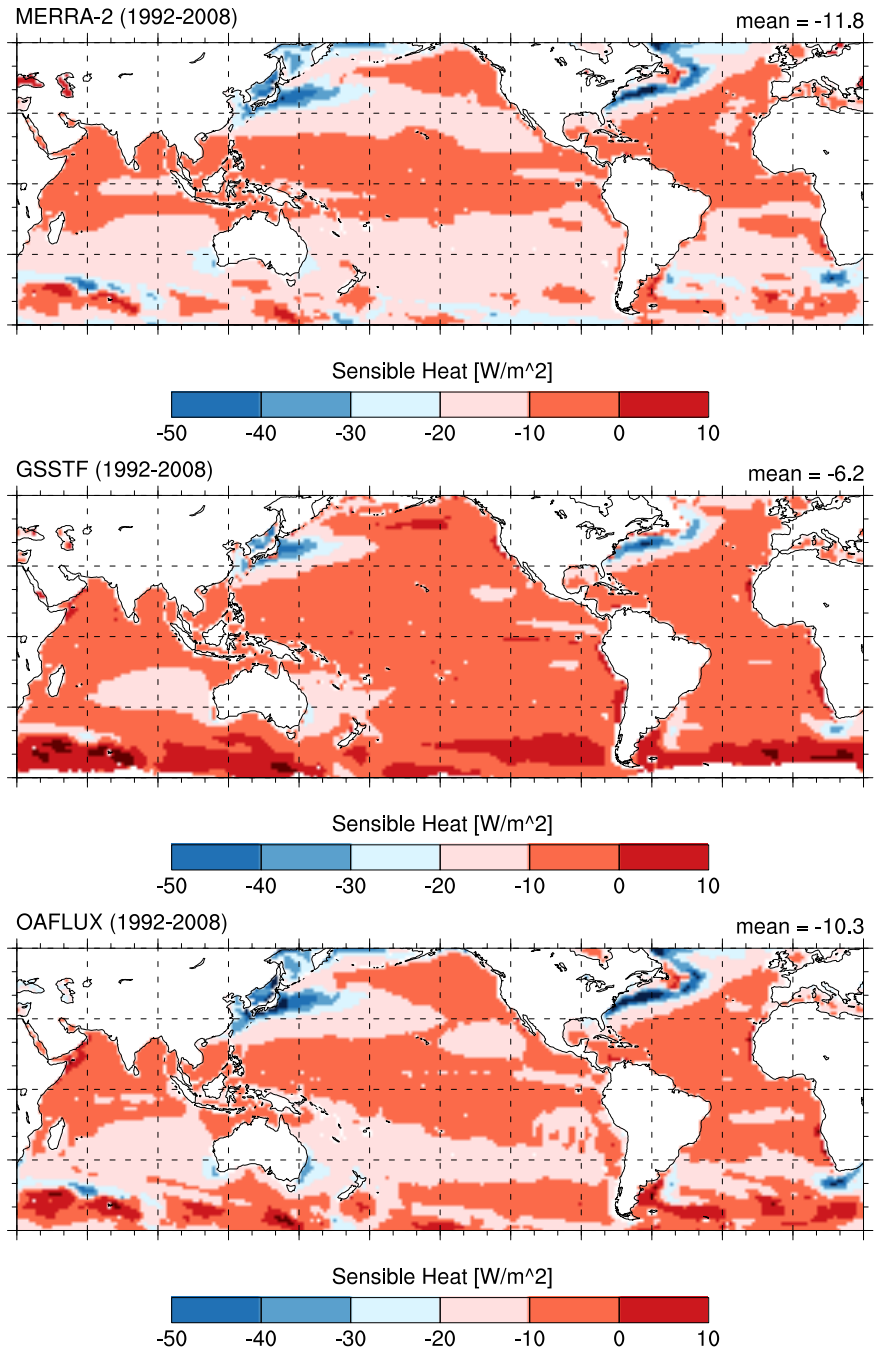
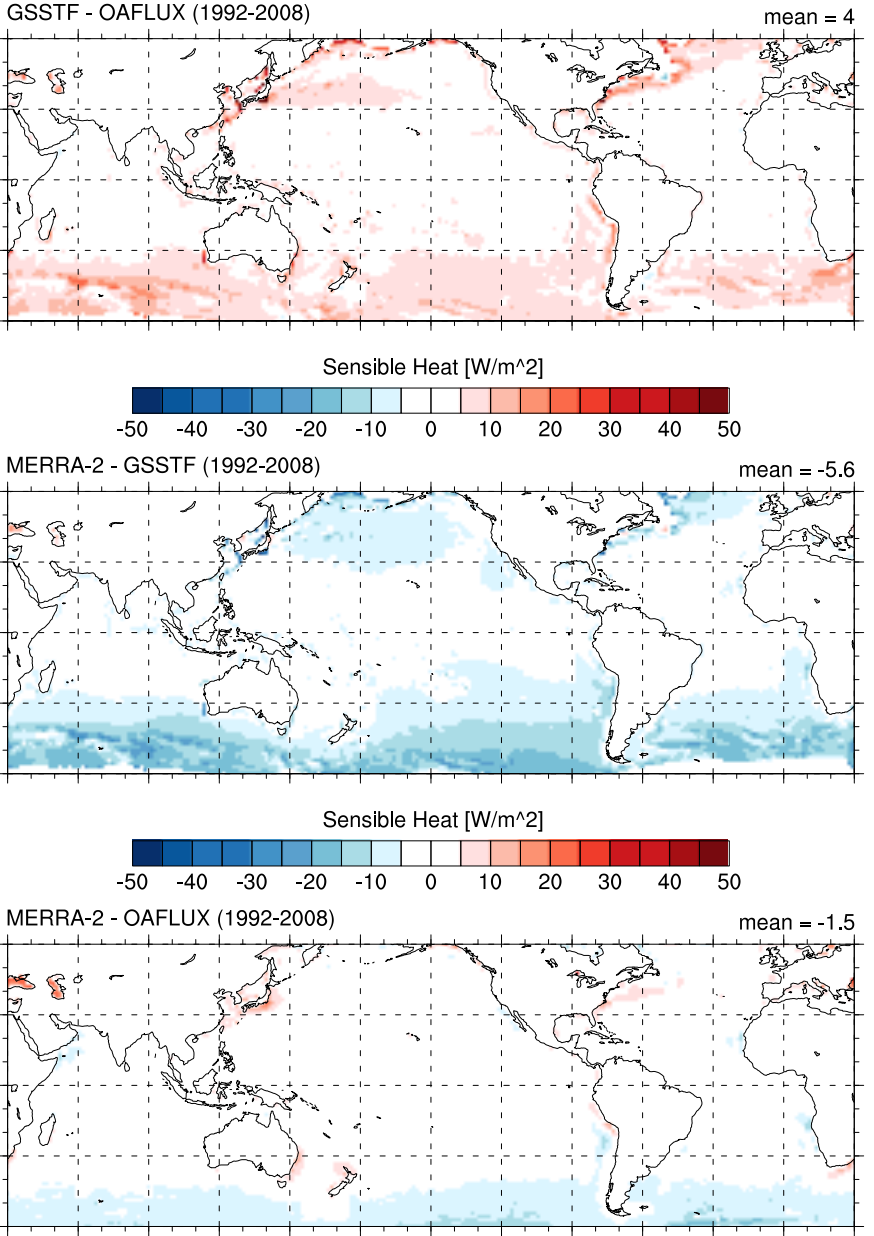

Sensible Heat $\left[\mathrm{W} / \mathrm{m}^{\wedge} 2\right]$

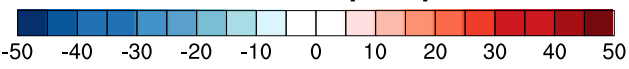

Figure A.2: Spatial distribution of mean sensible heat (positive downward).

research and applications, version 2 (merra-2). Journal of Climate 0 , null. doi:10.1175/JCLI-D-16-0758.1.

Griffies, S.M., Biastoch, A., Bning, C., Bryan, F., Danabasoglu, G., Chas-965 signet, E.P., England, M.H., Gerdes, R., Haak, H., Hallberg, R.W., Hazeleger, W., Jungclaus, J., Large, W.G., Madec, G., Pirani, A., Samuels, B.L., Scheinert, M., Gupta, A.S., Severijns, C.A., Simmons, H.L., Treguier, A.M., Winton, M., Yeager, S., Yin, J., 2009. Coordinated ocean-ice reference experiments (cores). Ocean Modelling 26, 1 - 46.970 doi:http://doi.org/10.1016/j.ocemod.2008.08.007.

Haney, R.L., 1971. Surface thermal boundary condition for ocean circulation models. Journal of Physical Oceanography 1, 241-248. doi:10.1175/15200485(1971)001;0241:STBCFO $i 2.0 . C O ; 2$.

Helfand, H.M., Schubert, S.D., 1995. Climatology of the simulated great 975 plains low-level jet and its contribution to the continental moisture budget of the united states. Journal of Climate 8, 784-806. doi:10.1175/15200442(1995)008;0784:COTSGP $; 2.0 . C O ; 2$.

955 Johnson, G.C., Lyman, J.M., Loeb, N.G., 2016. Improving estimates of earth's energy imbalance. Nature Climate Change 6, 639-640.980 doi:10.1038/nclimate3043.

Kalnay, E., Kanamitsu, M., Kistler, R., Collins, W., Deaven, D., Gandin, L., Iredell, M., Saha, S., White, G., Woollen, J., Zhu, Y., Leetmaa, A., Reynolds, R., Chelliah, M., Ebisuzaki, W., Higgins, W., Janowiak, J., Mo, K.C., Ropelewski, C., Wang, J., Jenne, R., Joseph, D., 1996. The ncep/ncar 40-985 year reanalysis project. Bulletin of the American Meteorological Society
77, 437-471. doi:10.1175/1520-0477(1996)077;0437:TNYRP;2.0.CO;2. Kobayashi, S., OTA, Y., HARADA, Y., EBITA, A., MORIYA, M., ONODA, H., ONOGI, K., KAMAHORI, H., KOBAYASHI, C., ENDO, H., MIYAOKA, K., TAKAHASHI, K., 2015. The jra-55 reanalysis: General specifications and basic characteristics. Journal of the Meteorological Society of Japan. Ser. II 93, 5-48. doi:10.2151/jmsj.2015-001.

Laloyaux, P., Balmaseda, M., Dee, D., Mogensen, K., Janssen, P., 2016. A coupled data assimilation system for climate reanalysis. Quarterly Journal of the Royal Meteorological Society 142, 65-78. doi:10.1002/qj.2629.

Large, W.G., Yeager, S.G., 2004. Diurnal to decadal global forcing for ocean and sea-ice models: the data sets and flux climatologies. National Center for Atmospheric Research Boulder.

Le Traon, P.Y., 2013. From satellite altimetry to argo and operational oceanography: three revolutions in oceanography. Ocean Science 9, 901-915. doi:10.5194/os-9-901-2013.

Lea, D.J., Mirouze, I., Martin, M.J., King, R.R., Hines, A., Walters, D., Thurlow, M., 2015. Assessing a new coupled data assimilation system based on the met office coupled atmospherelandoceansea ice model. Monthly Weather Review 143, 4678-4694. doi:10.1175/MWR-D-15-0174.1.

Legler, D., Freeland, H., Lumpkin, R., Ball, G., McPhaden, M., North, S., Crowley, R., Goni, G., Send, U., Merrifield, M., 2015. The current status of the real-time in situ global ocean observing system for operational oceanography. Journal of Operational Oceanography 8, s189-s200. doi:10.1080/1755876X.2015.1049883. 

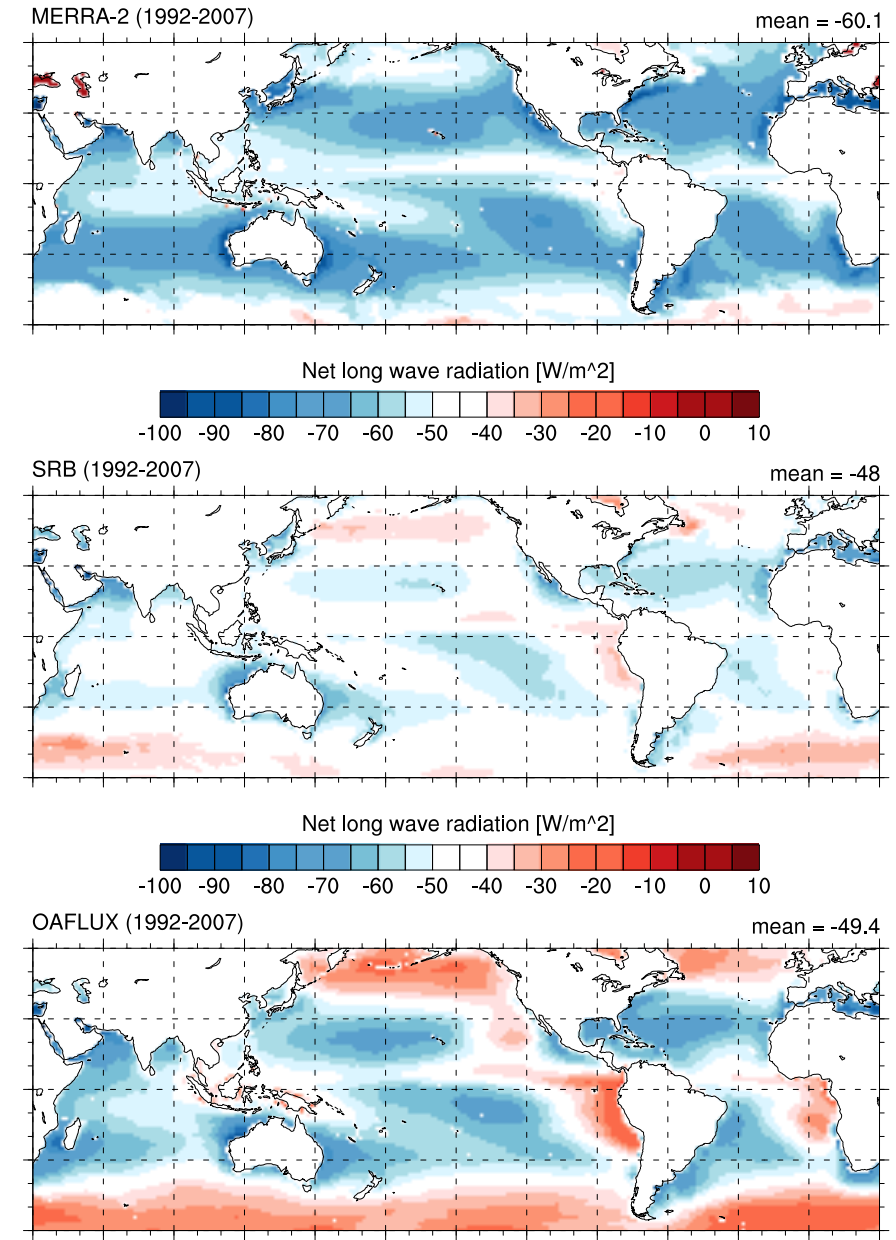

Net long wave radiation $\left[\mathrm{W} / \mathrm{m}^{\wedge} 2\right]$

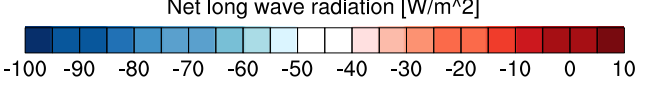

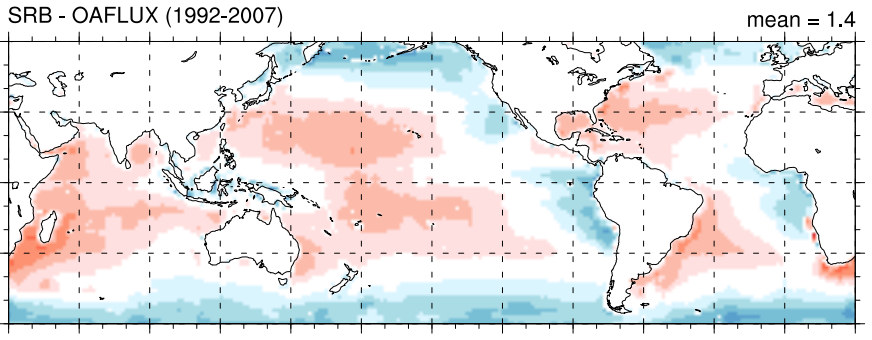
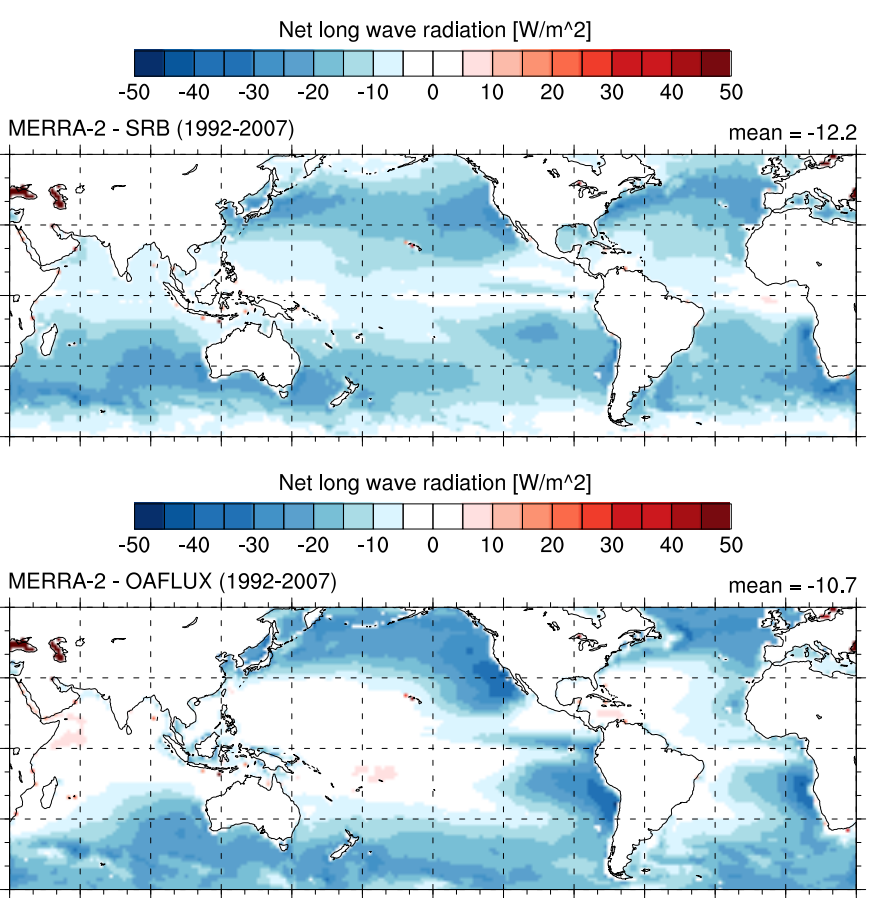

Net long wave radiation $\left[\mathrm{W} / \mathrm{m}^{\wedge} 2\right]$

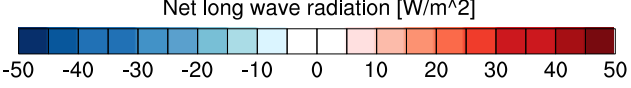

Figure A.3: Spatial distribution of mean net long wave radiation (positive downward).

Losch, M., Menemenlis, D., Campin, J.M., Heimbach, P., Hill, C., 2010. On the formulation of sea-ice models. part 1: Effects of different solver implementations and parameterizations. Ocean Modelling 33, $129-144$. doi:http://doi.org/10.1016/j.ocemod.2009.12.008.

Marshall, J., Adcroft, A., Hill, C., Perelman, L., Heisey, C., 1997. A finite 4015 volume, incompressible navier stokes model for studies of the ocean on parallel computers. Journal of Geophysical Research: Oceans 102, 5753-5766. doi:10.1029/96JC02775.

Mogensen, K.S., Magnusson, L., Bidlot, J.R., 2017. Tropical cyclone sensitivity to ocean coupling in the ecmwf coupled model. Journal of Geophysicaloro Research: Oceans 122, 4392-4412. doi:10.1002/2017JC012753.

Molod, A., Suarez, M., Partyka, G., 2013. The impact of limiting ocean roughness on geos-5 agcm tropical cyclone forecasts. Geophysical Research Letters 40, 411-416. doi:10.1029/2012GL053979.

Molod, A., Takacs, L., Suarez, M., Bacmeister, J., 2015. Development of 025 the geos-5 atmospheric general circulation model: evolution from merra to merra2. Geoscientific Model Development 8, 1339-1356. doi:10.5194/gmd8-1339-2015.

OAFLUX, 2018. Project description: Oaflux surface heat fluxes. URL: http://oaflux.whoi.edu/descriptionheatflux.html.

Putman, W., Lin, S.J., 2009. A finite-volume dynamical core on the cubedsphere grid, in: Numerical Modeling of Space Plasma Flows: Astronum2008, p. 268.

1010 Reynolds, R.W., Rayner, N.A., Smith, T.M., Stokes, D.C., Wang, W., 2002. An improved in situ and satellite sst analysis for climate. Journal of Climate 15, 1609-1625. doi:10.1175/1520-0442(2002)015;1609:AIISAS $; 2.0 . C O ; 2$.

Reynolds, R.W., Smith, T.M., Liu, C., Chelton, D.B., Casey, K.S., Schlax, M.G., 2007. Daily high-resolution-blended analyses for sea surface temperature. Journal of Climate 20, 5473-5496. doi:10.1175/2007JCLI1824.1.

Rienecker, M., Suarez, M.J., Todling, R., Bacmeister, J., Takacs, L., Liu, H., Gu, W., Sienkiewicz, M., Koster, R., Gelaro, R., Stajner, I., Nielsen, J., 2008. The geos-5 data assimilation system-documentation of versions 5.0. 1, 5.1. 0, and 5.2. 0. Technical Report Series .

Rutan, D.A., Kato, S., Doelling, D.R., Rose, F.G., Nguyen, L.T., Caldwell, T.E., Loeb, N.G., 2015. Ceres synoptic product: Methodology and validation of surface radiant flux. Journal of Atmospheric and Oceanic Technology 32, 1121-1143. doi:10.1175/JTECH-D-14-00165.1.

Saha, S., Moorthi, S., Pan, H.L., Wu, X., Wang, J., Nadiga, S., Tripp, P., Kistler, R., Woollen, J., Behringer, D., Liu, H., Stokes, D., Grumbine, R., Gayno, G., Wang, J., Hou, Y.T., Chuang, H.Y., Juang, H.M.H., Sela, J., Iredell, M., Treadon, R., Kleist, D., Delst, P.V., Keyser, D., Derber, J., Ek, M., Meng, J., Wei, H., Yang, R., Lord, S., Dool, H.V.D., Kumar, A., Wang, W., Long, C., Chelliah, M., Xue, Y., Huang, B., Schemm, J.K., Ebisuzaki, W., Lin, R., Xie, P., Chen, M., Zhou, S., Higgins, W., Zou, C.Z., Liu, Q., Chen, Y., Han, Y., Cucurull, L., Reynolds, R.W., Rutledge, G., Goldberg, M., 2010. The ncep climate forecast system reanalysis. Bulletin of the American Meteorological Society 91, 1015-1057. doi:10.1175/2010BAMS3001.1.

Schiller, A., Davidson, F., DiGiacomo, P.M., Wilmer-Becker, K., 2016. Bet- 


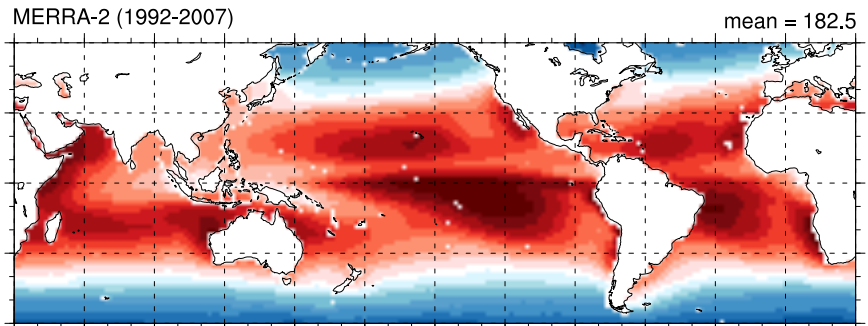

Net short wave radiation $\left[\mathrm{W} / \mathrm{m}^{\wedge} 2\right]$
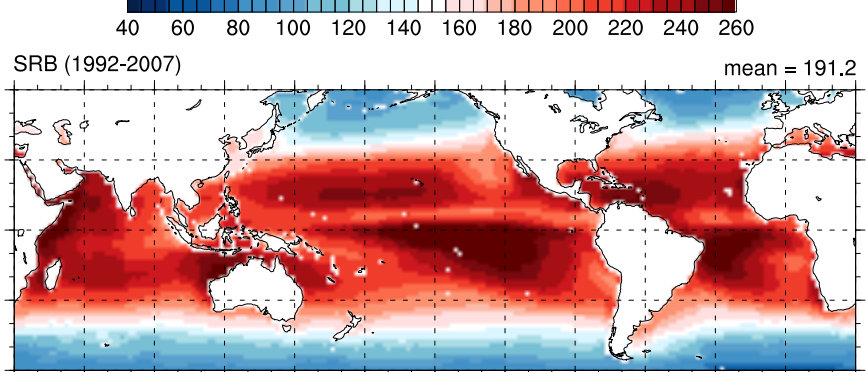

Net short wave radiation $\left[\mathrm{W} / \mathrm{m}^{\wedge} 2\right]$

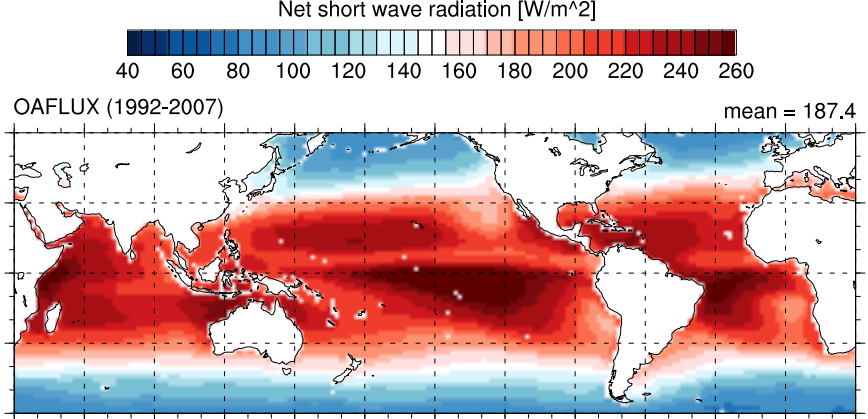

Net short wave radiation $\left[\mathrm{W} / \mathrm{m}^{\wedge} 2\right]$

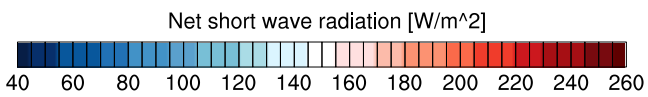

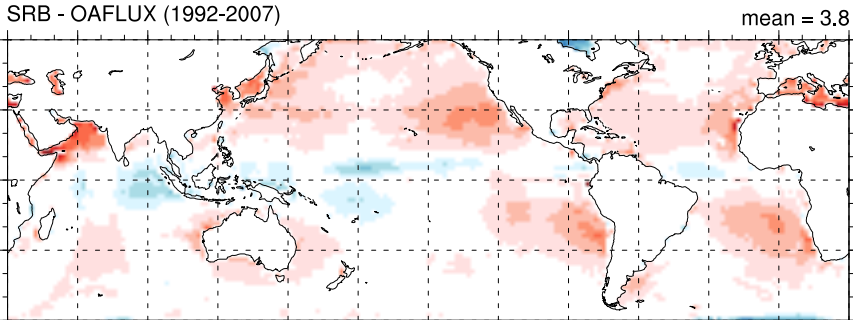

Net short wave radiation $\left[\mathrm{W} / \mathrm{m}^{\wedge} 2\right]$
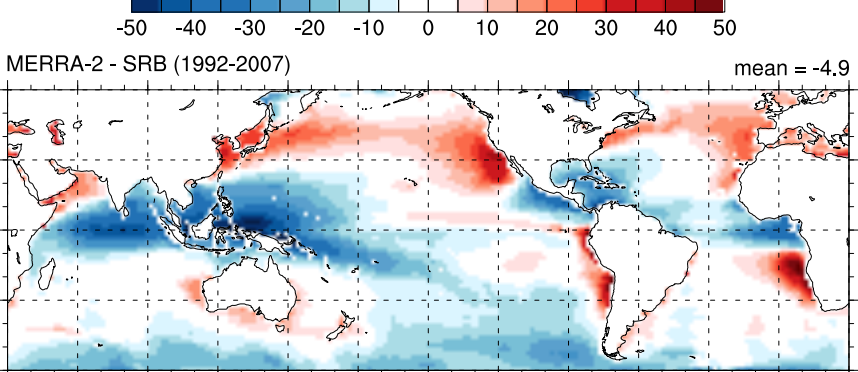

Net short wave radiation $\left[\mathrm{W} / \mathrm{m}^{\wedge} 2\right]$
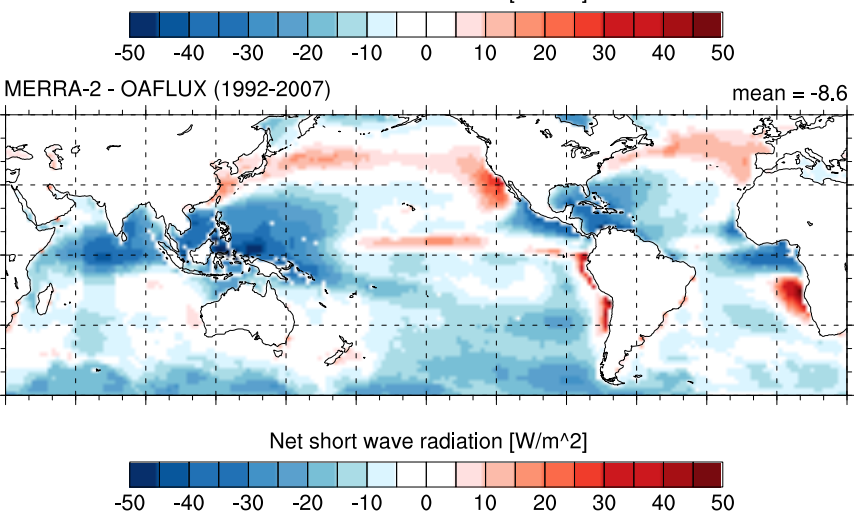

Figure A.4: Spatial distribution of mean net short wave radiation (positive downward).

ter informed marine operations and management: Multidisciplinary efforts in ocean forecasting research for socioeconomic benefit. Bulletin of the060 American Meteorological Society 97, 1553-1559. doi:10.1175/BAMS-D15-00102.1.

Schmit, T.J., Griffith, P., Gunshor, M.M., Daniels, J.M., Goodman, S.J., Lebair, W.J., 2017. A closer look at the abi on the goes-r series. Bulletin of the American Meteorological Society 98, 681-698. doi:10.1175/BAMS-D-15+065 00230.1 .

Seager, R., Kushnir, Y., Cane, M.A., 1995. On heat flux boundary conditions for ocean models. Journal of Physical Oceanography 25, 3219-3230. doi:10.1175/1520-0485(1995)025;3219:OHFBCFi2.0.CO;2.

Stackhouse Jr, P.W., Gupta, S.K., Cox, S.J., Zhang, T., Mikovitz, J.C., Hinkel+070 man, L.M., 2011. The nasa/gewex surface radiation budget release 3.0: 24.5year dataset. Gewex news 21, 10-12.

Stammer, D., Wunsch, C., Giering, R., Eckert, C., Heimbach, P., Marotze, J., Adcroft, A., Hill, C.N., Marshall, J., 2002. Global ocean circulation during 1992-1997, estimated from ocean observations and a general circulationo75 model. Journal of Geophysical Research 107, 3118-1-27.

von Storch, H., Zwiers, F.W., 1999. Statistical Analysis in Climate Research. 1 ed., Cambridge University Press.

Taylor, K.E., Williamson, D., Zwiers, F., 2000. The sea surface temperature and sea-ice concentration boundary conditions for AMIP II simulations. Pro 4080 gram for Climate Model Diagnosis and Intercomparison, Lawrence Livermore National Laboratory, University of California.
Trenberth, K.E., Fasullo, J.T., von Schuckmann, K., Cheng, L., 2016. Insights into earths energy imbalance from multiple sources. Journal of Climate 29, 7495-7505. doi:10.1175/JCLI-D-16-0339.1.

Valdivieso, M., Haines, K., Balmaseda, M., Chang, Y.S., Drevillon, M., Ferry, N., Fujii, Y., Köhl, A., Storto, A., Toyoda, T., Wang, X., Waters, J., Xue, Y., Yin, Y., Barnier, B., Hernandez, F., Kumar, A., Lee, T., Masina, S., Andrew Peterson, K., 2017. An assessment of air-sea heat fluxes from ocean and coupled reanalyses. Climate Dynamics 49, 983-1008. doi:10.1007/s00382-015-2843-3.

Wang, W., Xie, P., Yoo, S.H., Xue, Y., Kumar, A., Wu, X., 2011. An assessment of the surface climate in the ncep climate forecast system reanalysis. Climate Dynamics 37, 1601-1620. doi:10.1007/s00382-010-0935-7.

Wunsch, C., 2006. Discrete inverse and state estimation problems: with geophysical fluid applications. Cambridge University Press.

Wunsch, C., Heimbach, P., Ponte, R., Fukumori, I., 2009. The Global General Circulation of the Ocean Estimated by the ECCO-Consortium. Oceanography 22, 88-103.

Yu, L., Weller, R.A., 2007. Objectively analyzed airsea heat fluxes for the global ice-free oceans (19812005). Bulletin of the American Meteorological Society 88, 527-539. doi:10.1175/BAMS-88-4-527.

Zhang, Y., Rossow, W.B., Lacis, A.A., Oinas, V., Mishchenko, M.I., 2004. Calculation of radiative fluxes from the surface to top of atmosphere based on isccp and other global data sets: Refinements of the radiative transfer model and the input data. Journal of Geophysical Research: Atmospheres 


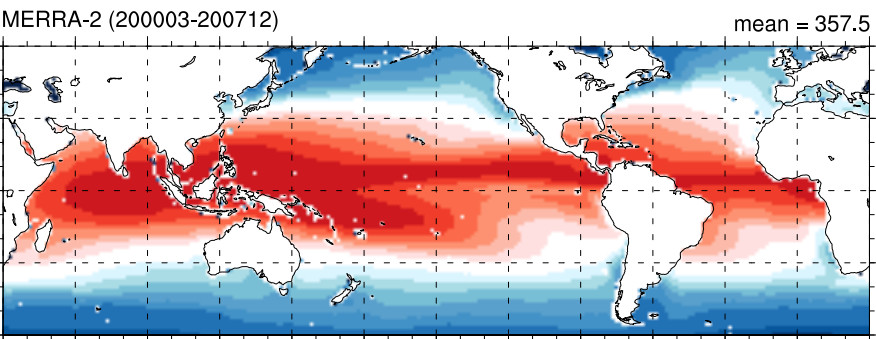

Downward long wave radiation $\left[\mathrm{W} / \mathrm{m}^{\wedge} 2\right]$

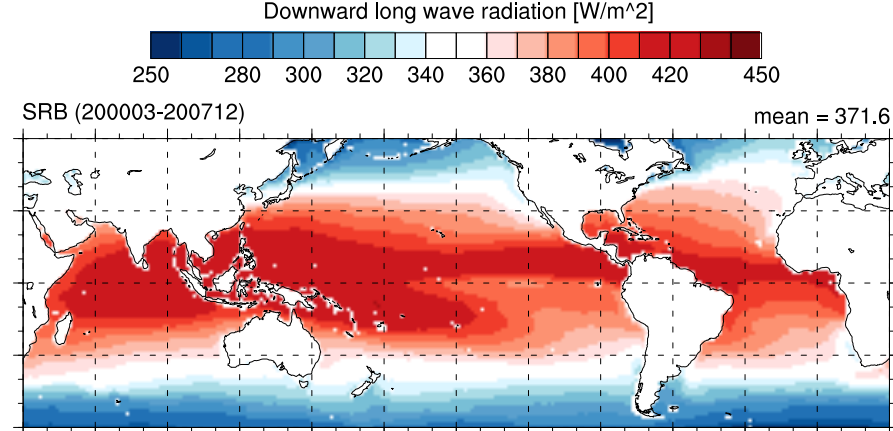

Downward long wave radiation $\left[\mathrm{W} / \mathrm{m}^{\wedge} 2\right]$
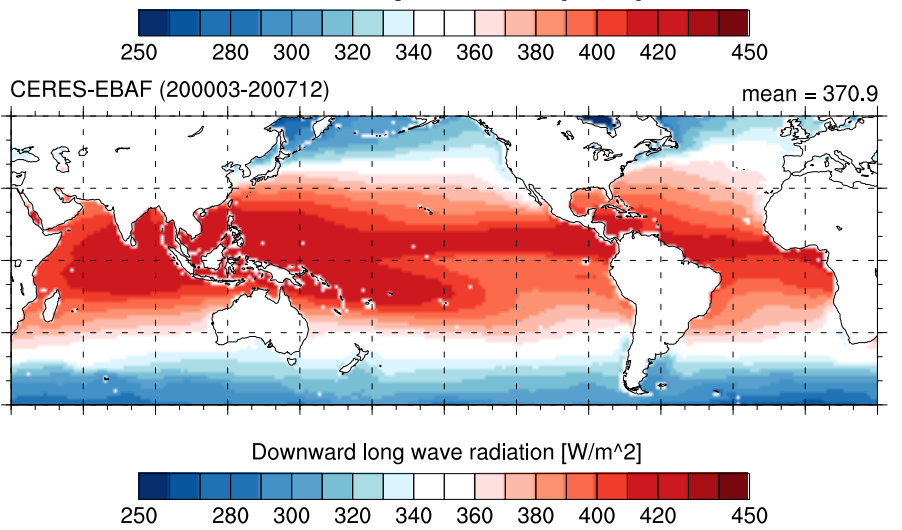

SRB - CERES-EBAF (200003-200712)

mean $=0.7$

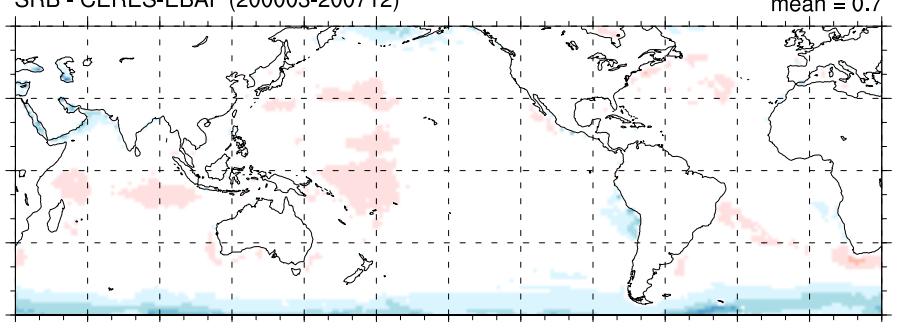

Downward long wave radiation $\left[\mathrm{W} / \mathrm{m}^{\wedge} 2\right]$

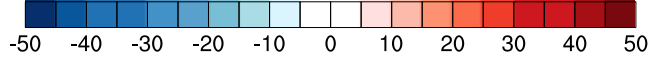

MERRA-2 - SRB (200003-200712) mean $=-13.4$
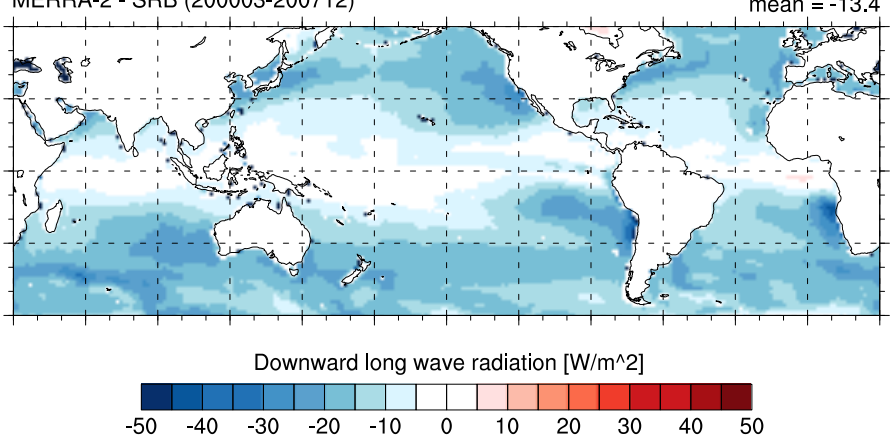

MERRA-2 - CERES-EBAF (200003-201112) mean $=-14.1$

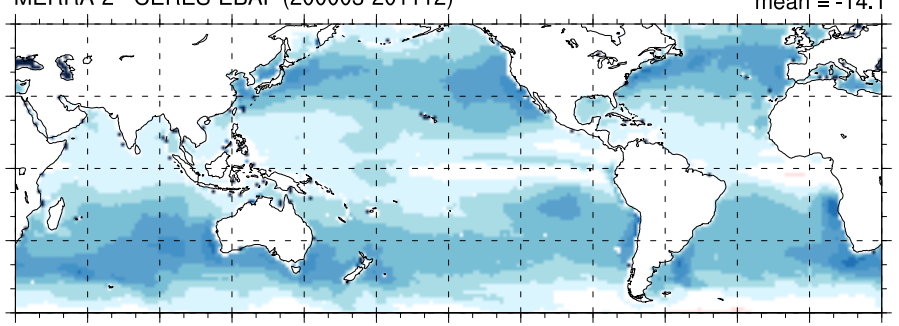

Downward long wave radiation $\left[\mathrm{W} / \mathrm{m}^{\wedge} 2\right]$

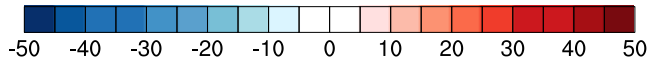

Figure A.5: Spatial distribution of mean downward long wave radiation (positive downward).

109, n/a-n/a. doi:10.1029/2003JD004457. d19105.

Zuidema, P., Chang, P., Medeiros, B., Kirtman, B.P., Mechoso, R., Schneider, E.K., Toniazzo, T., Richter, I., Small, R.J., Bellomo, K., Brandt, P., de Szoeke, S., Farrar, J.T., Jung, E., Kato, S., Li, M., Patricola, C., Wang, Z., Wood, R., Xu, Z., 2016. Challenges and prospects for reducing coupled climate model sst biases in the eastern tropical atlantic and pacific oceans: The u.s. clivar eastern tropical oceans synthesis working group. Bulletin of the American Meteorological Society 97, 2305-2328. doi:10.1175/BAMSD-15-00274.1. 


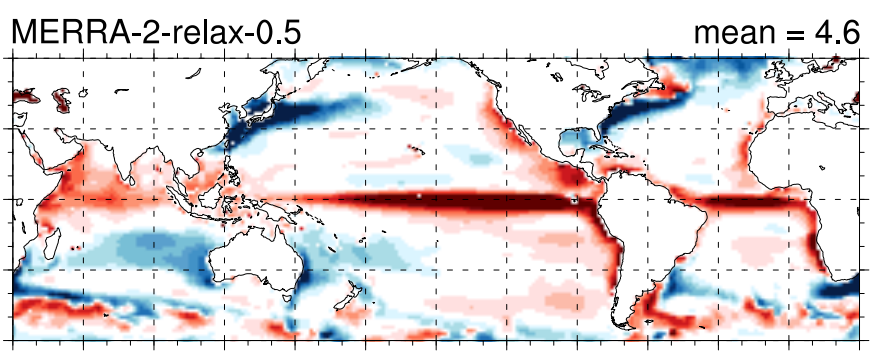

Net heat flux [W/m^2]
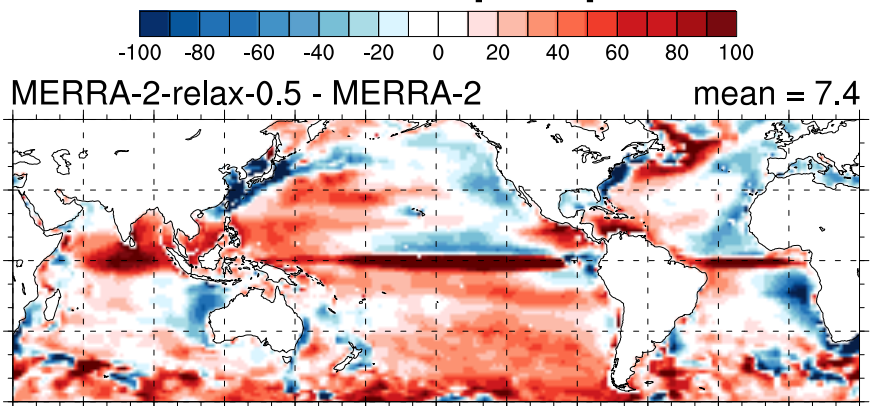

Net heat flux [W/m^2]
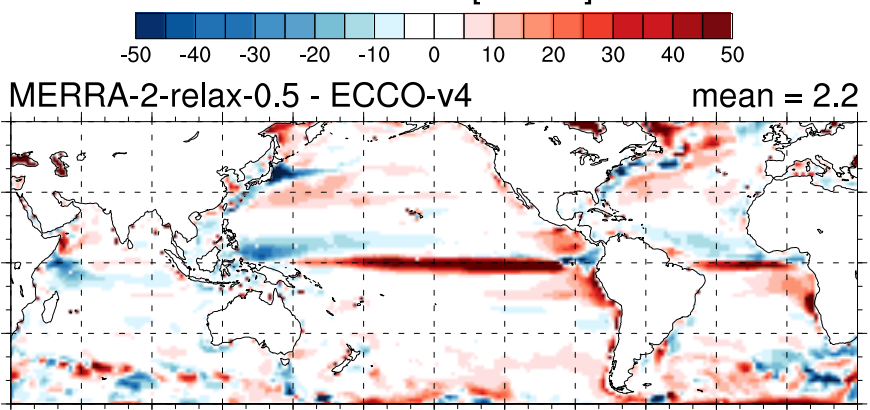

Net heat flux [W/m^2]

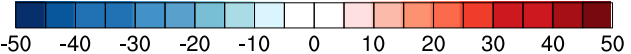

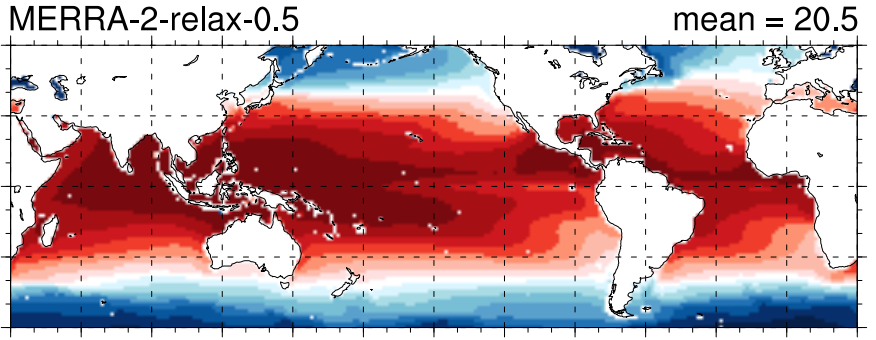

SST [DegC]
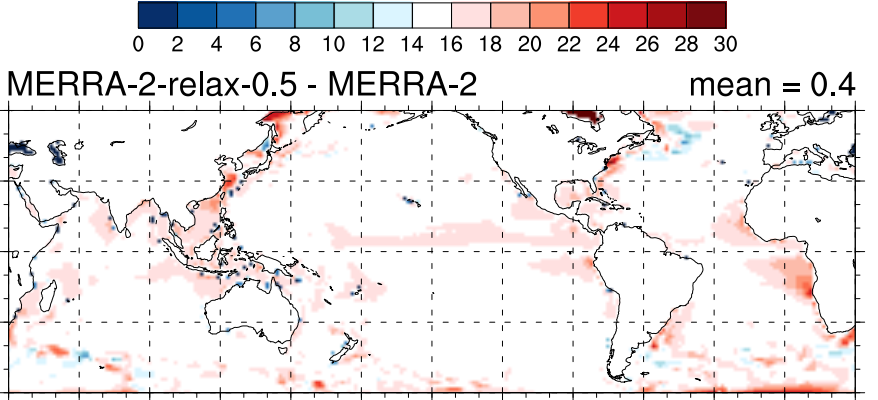

SST [DegC]
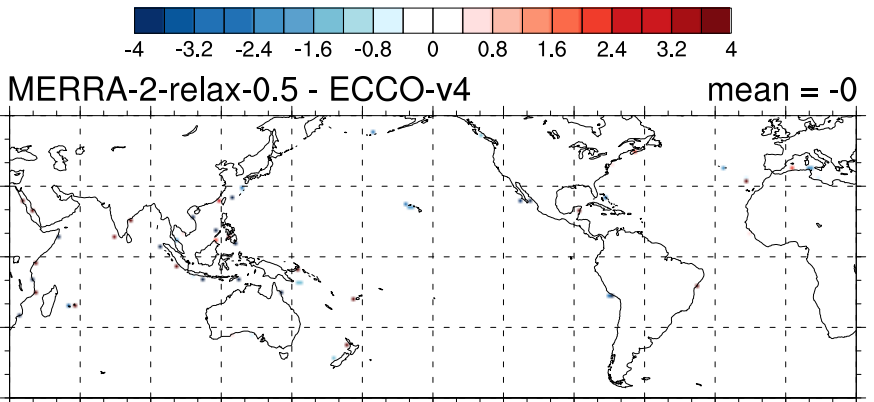

SST [DegC]

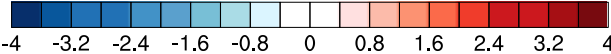

Figure B.1: MERRA-2-flux with 0.5 day relaxation time scale. The spatial distribution of 20-year average of net total heat flux (in $\mathrm{W}$ m ${ }^{-2}$ ); and $\mathrm{SST}$ (in ${ }^{\circ} \mathrm{C}$ ). The first row shows MERRA-2-relax, the second row shows MERRA-2-relax minus the original MERRA-2, and the third column shows MERRA-2-relax minus ECCO-v4. 


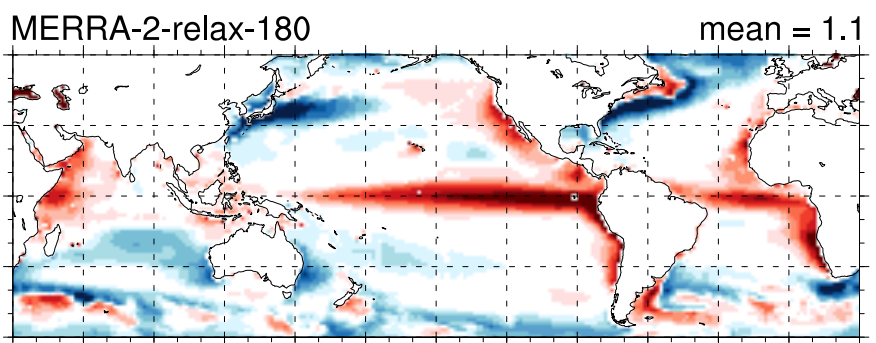

Net heat flux [W/m^2]
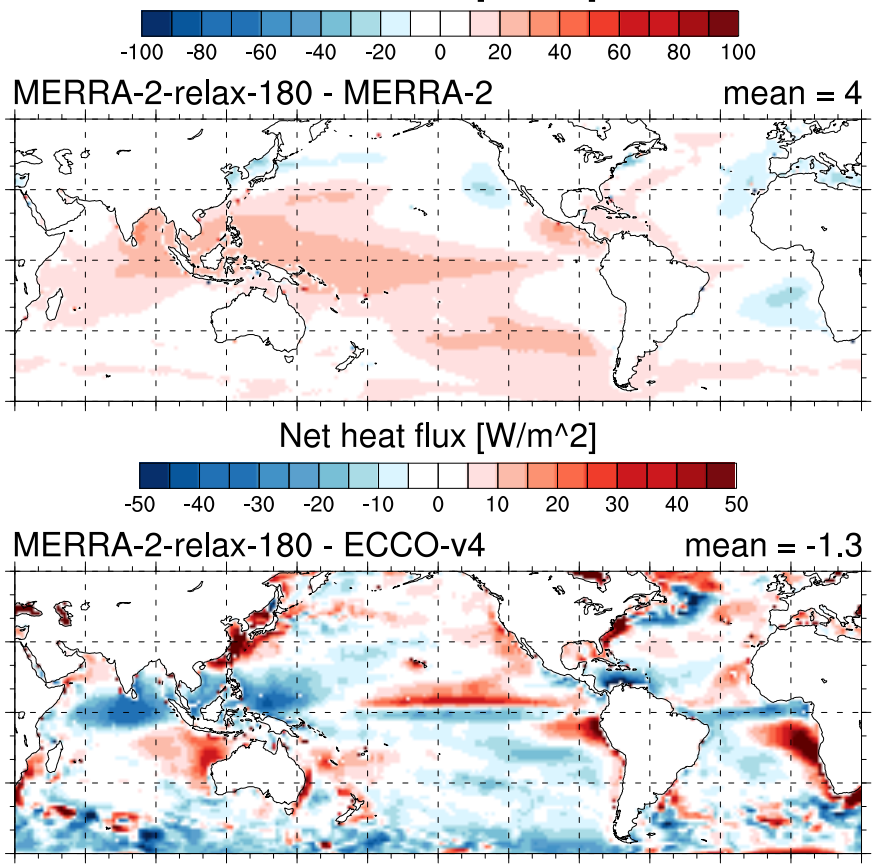

Net heat flux [W/m^2]

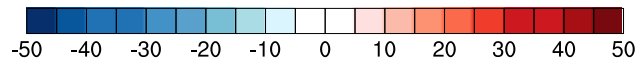

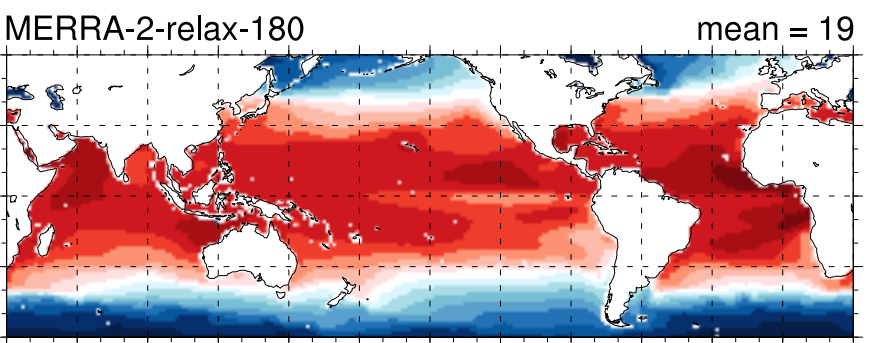

SST [DegC]
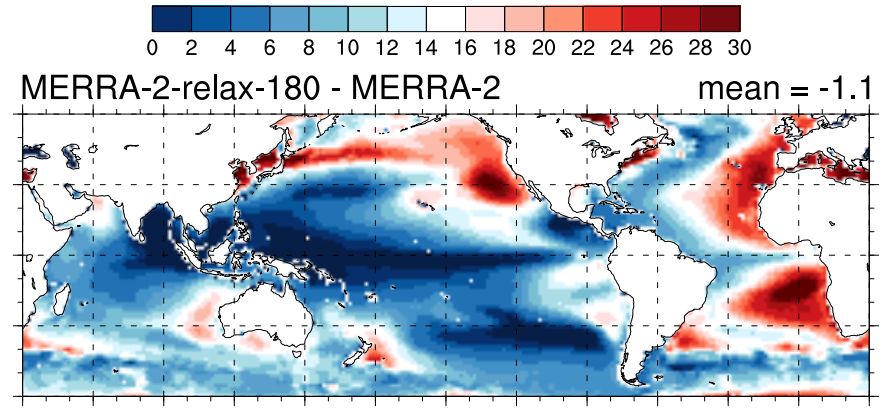

SST [DegC]
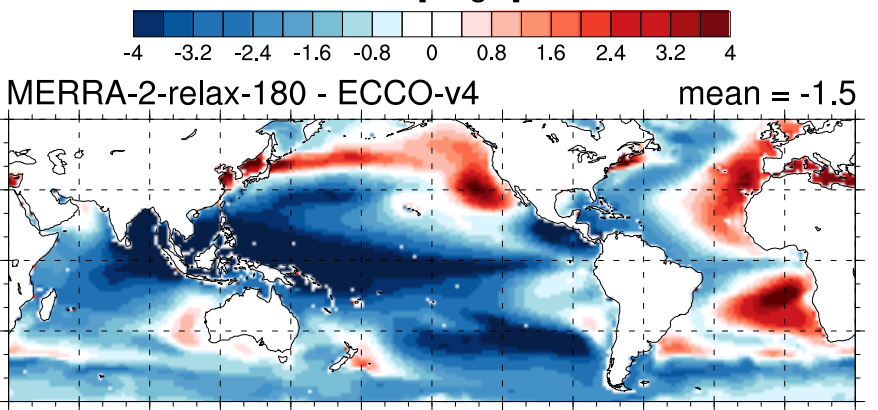

\section{SST [DegC]}

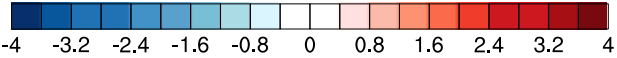

Figure B.2: MERRA-2-flux with 90 days relaxation time scale. The spatial distribution of 20-year average of net total heat flux (in $\mathrm{W}$ m ${ }^{-2}$ ); and SST (in ${ }^{\circ} \mathrm{C}$ ). The first row shows MERRA-2-turb, the second row shows MERRA-2-relax minus the original MERRA-2, and the third row shows MERRA-2-relax minus ECCO-v4. 


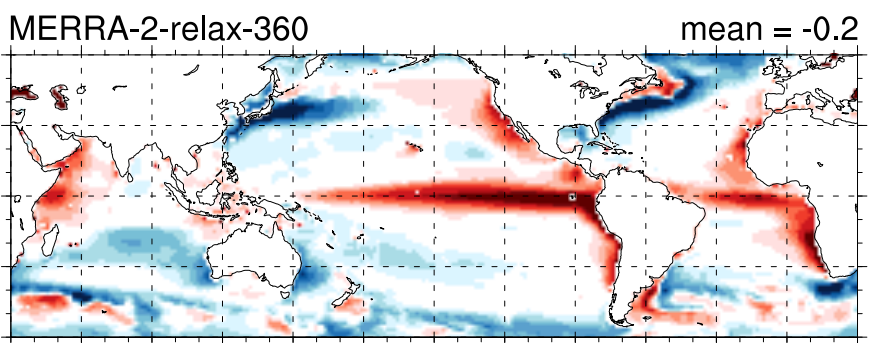

Net heat flux $\left[\mathrm{W} / \mathrm{m}^{\wedge} 2\right]$
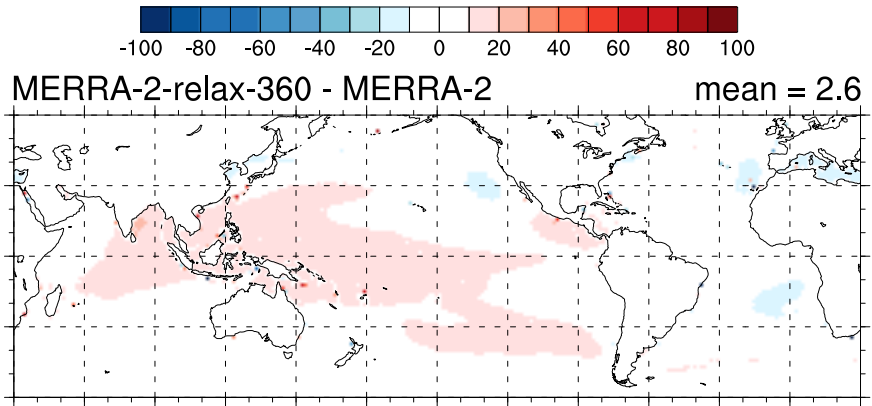

Net heat flux [W/m^2]
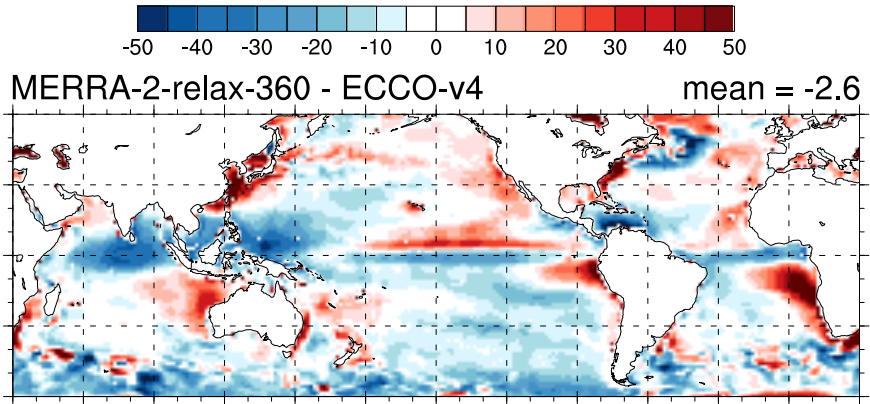

Net heat flux [W/m^2]

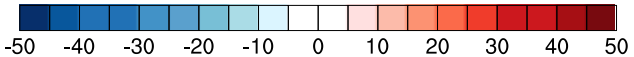

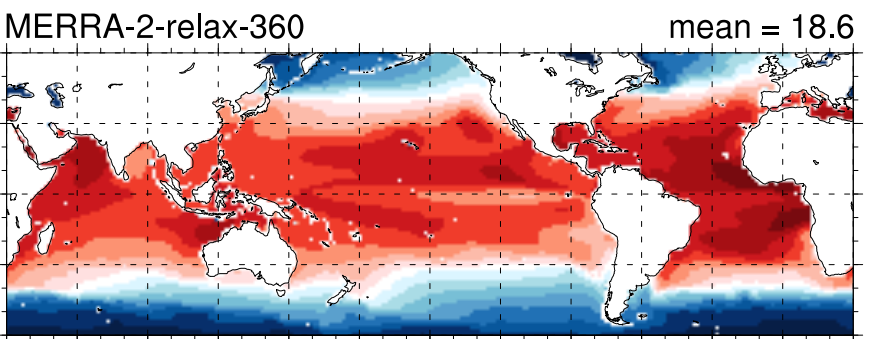

SST [DegC]
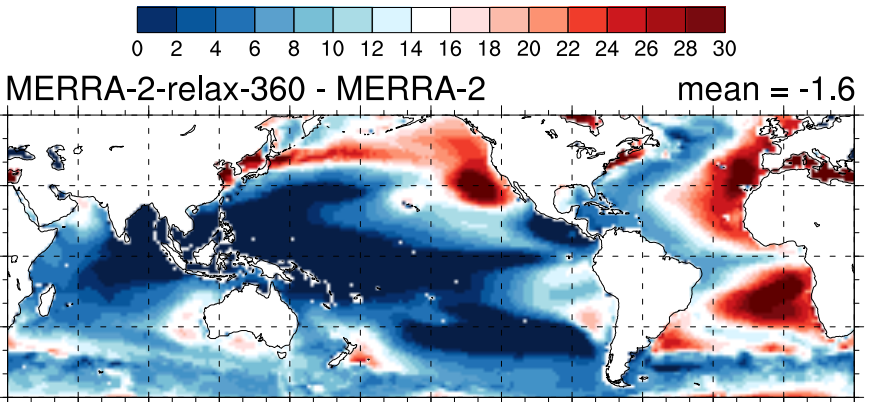

SST [DegC]
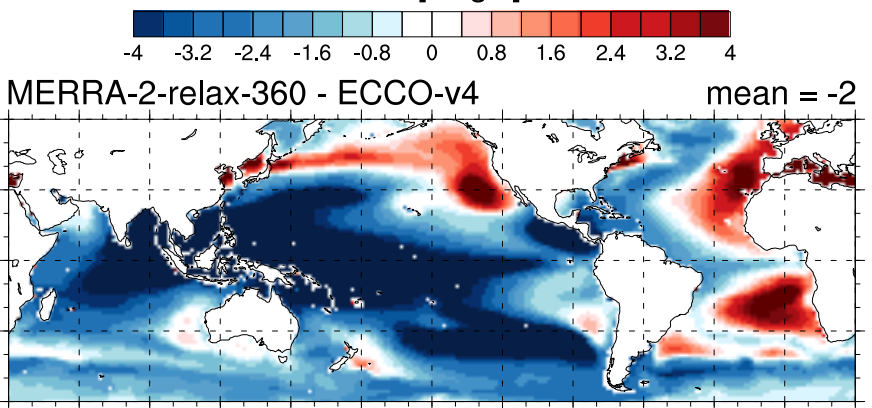

SST [DegC]

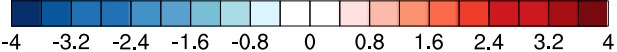

Figure B.3: MERRA-2-flux with 360 days relaxation time scale. The spatial distribution of 20 -year average of net total heat flux (in $\mathrm{W}$ m ${ }^{-2}$ ); and SST (in ${ }^{\circ} \mathrm{C}$ ). The first row shows MERRA-2-relax, the second row shows MERRA-2-relax minus the original MERRA-2, and the third row shows MERRA-2-relax minus ECCO-v4. 

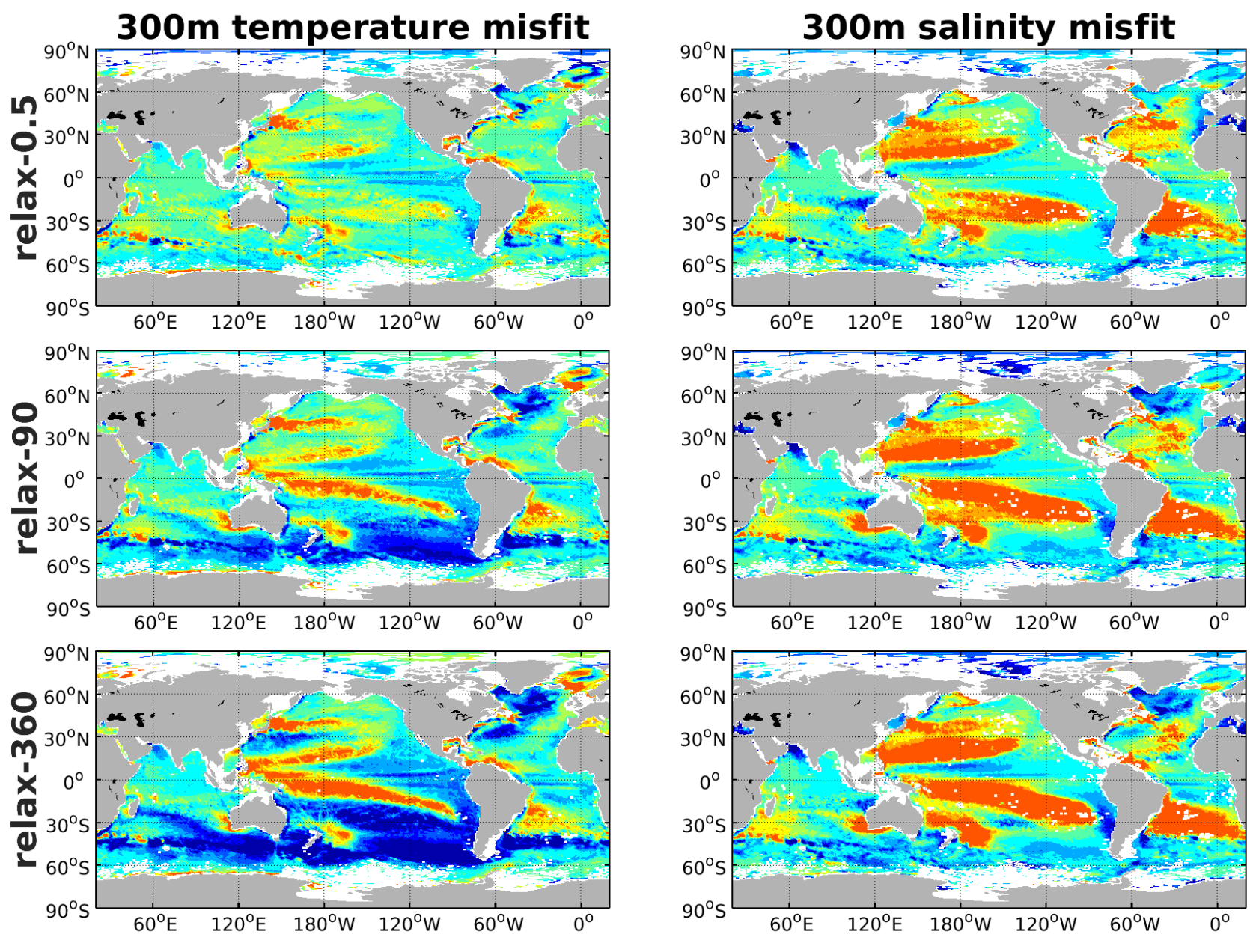

$\begin{array}{lllllllllll}-2 & -1.6 & -1.2 & -0.8 & -0.4 & 0 & 0.4 & 0.8 & 1.2 & 1.6 & 2\end{array}$

$\begin{array}{llllllllll}-0.3-0.24-0.18-0.12-0.06 & 0 & 0.06 & 0.12 & 0.18 & 0.24 & 0.3\end{array}$

Figure B.4: Time mean misfit (model-data) for in situ profiles at $300 \mathrm{~m}$ for $\mathrm{T}$ (left; in ${ }^{\circ} \mathrm{C}$ ) and $\mathrm{S}$ (right; in psu). 